\title{
Reconstitution of monoterpene indole alkaloid biosynthesis in Nicotiana benthamiana
}

\author{
Quentin M. Dudley ${ }^{1}$, Seohyun Jo ${ }^{1}$, Delia Ayled Serna Guerrero², \\ Sarah E. O'Connor ${ }^{2}$, Lorenzo Caputi ${ }^{2 *}$, Nicola J. Patron ${ }^{1 *}$ \\ ${ }^{1}$ Engineering Biology, Earlham Institute, Norwich Research Park, Norwich, Norfolk, NR4 7UZ, UK; \\ 2 Department of Natural Product Biosynthesis, Max Planck Institute for Chemical Ecology, Jena \\ 07745, Germany
}

*Correspondence: nicola.patron@earlham.ac.uk, Icaputi@ice.mpg.de

\begin{abstract}
Monoterpene indole alkaloids (MIAs) are a diverse and important class of plant natural products that include a number of medicinally significant compounds, often present at low concentrations within their native plant species. The complex biosynthesis of MIAs requires the assembly of tryptamine with a secoiridoid to produce the central intermediate, strictosidine, from which all known MIAs derive. Structural complexity makes chemical synthesis challenging, but recent efforts to identify the biosynthetic enzymes provide options for pathway reconstruction in a heterologous host. Previous attempts have had limited success, with yield in microorganisms limited by the poor expression of some enzymes. Here, we reconstitute the pathway for strictosidine biosynthesis from central metabolism without the need for supplementation of any metabolite precursors or intermediates in Nicotiana benthamiana. The best yields were obtained by the co-expression of 14 enzymes, of which a major latex protein-like enzyme (MLPL) from Nepeta (catmint) was critical for improving flux through the secoiridoid pathway. The production of strictosidine in planta expands the range of MIA products amenable to biological synthesis.
\end{abstract}

Key words: monoterpene indole alkaloid; strictosidine; secologanin; Catharanthus roseus; Nicotiana benthamiana

\section{Introduction}

Monoterpene indole alkaloids (MIAs) are a large group of plant-produced natural products of which over 3000 have been identified (Pan et al. 2016). This class of molecules includes many medicinally valuable compounds used to treat addiction, heart conditions, dementia, pain, cancer, malaria, and diabetes (Figure 1). The best characterised MIA-producing plant is Catharanthus roseus (Madagascar periwinkle), which makes over 130 MIAs including the bioactive vinblastine and vincristine used as chemotherapies. However, these valuable molecules are present in low concentrations $(0.0005 \%$ dry weight) (van Der Heijden et al. 2004), limiting production. Mass cultivation of $C$. roseus cells is feasible, but a high producing cell line has yet to be reported (Saiman et al. 2018). Though methods for transient expression (Yamamoto et al. 2021) and stable genetic transformation (Q. Wang et al. 2012) of $C$. roseus plants have been reported, genetically engineering yield increases within the native plant host remains technically difficult. Furthermore, the structural complexity of many MIAs means chemical synthesis is often challenging (Ishikawa et al. 2009; Kuboyama et al. 2004). Consequently, alternate routes for synthesis are desirable and the recent discovery of missing steps in the vinblastine pathway (Caputi et al. 2018; Qu et al. 2018) makes pathway reconstruction in a heterologous host an increasingly attractive option.

Achieving production of therapeutically useful amounts of MIAs requires pathway engineering to maximise metabolic flux through the early parts of the pathway. Strictosidine is the last common biosynthetic intermediate from which all 3000+ known MIAs derive (Figure 1). Reconstitution of its $\sim 11$ step biosynthetic pathway in microorganisms can require extensive tuning of enzyme expression conditions and strain optimization (Brown et al. 2015; Billingsley et al. 2017); for example, poor expression of geraniol 8-hydroxylase $(\mathrm{G} 8 \mathrm{H})$ has hampered strictosidine production in yeast (Brown et al. 2015). Achieving useful yields of molecules such as vinblastine, which would require the expression of a further 16+ enzymes beyond strictosidine, is therefore likely to require significant metabolic engineering effort. 
The application of synthetic biology approaches to engineering plant systems has facilitated advances in the control and expression of biosynthetic pathways, enabling plants as an alternative production chassis (Patron 2020; Stephenson et al. 2020). A relative of tobacco, Nicotiana benthamiana (Bally et al. 2018; Goodin et al. 2008) has emerged as a favoured species for plantbased production of pharmaceutical proteins (Lomonossoff and D'Aoust 2016) and metabolic pathway reconstitution (Stephenson et al. 2020). Successes include gram scale production of triterpenoids (Reed et al. 2017) and milligram scale production of etoposides (Schultz et al. 2019). Indeed, expression in $N$. benthamiana was used by Miettinen and co-workers to reconstitute the $C$. roseus secoiridoid pathway, enabling elucidation of the remaining four missing steps of the pathway (Miettinen et al. 2014). However, they encountered a metabolic bottleneck midway through the 13step pathway requiring reconstitution in two phases with the latter part requiring provision of an intermediate substrate (iridotrial) in order to obtain strictosidine (Miettinen et al. 2014). In this work, we show that co-expression of additional pathway enzymes enhances nepetalactol production and enables high levels of strictosidine to be produced from the central metabolism of $N$. benthamiana without the need for supplementation of any metabolite precursors or intermediates.
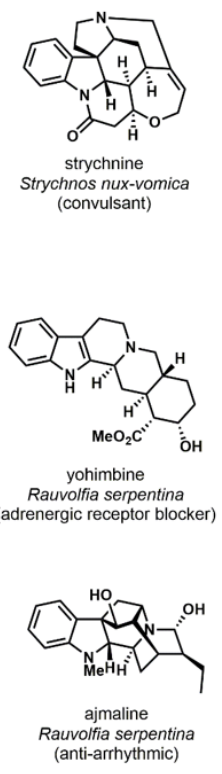
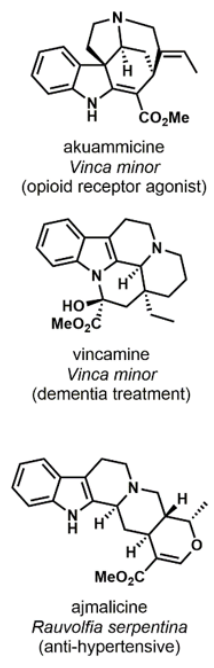$$
\begin{aligned}
& \text { akuammicine } \\
& \text { Vinca minor }
\end{aligned}
$$
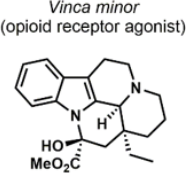$$
\text { vincamine }
$$$$
\text { (dementia treatment) }
$$

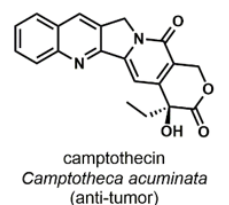

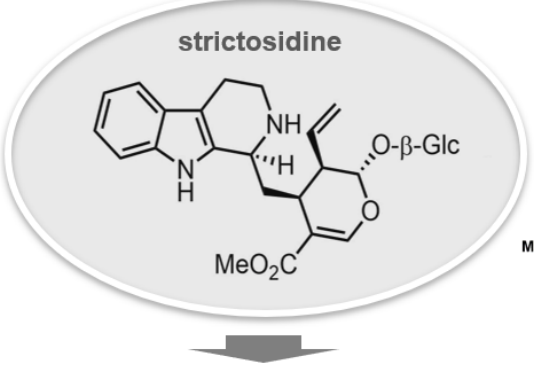

Monoterpene indole alkaloids (MIAs)
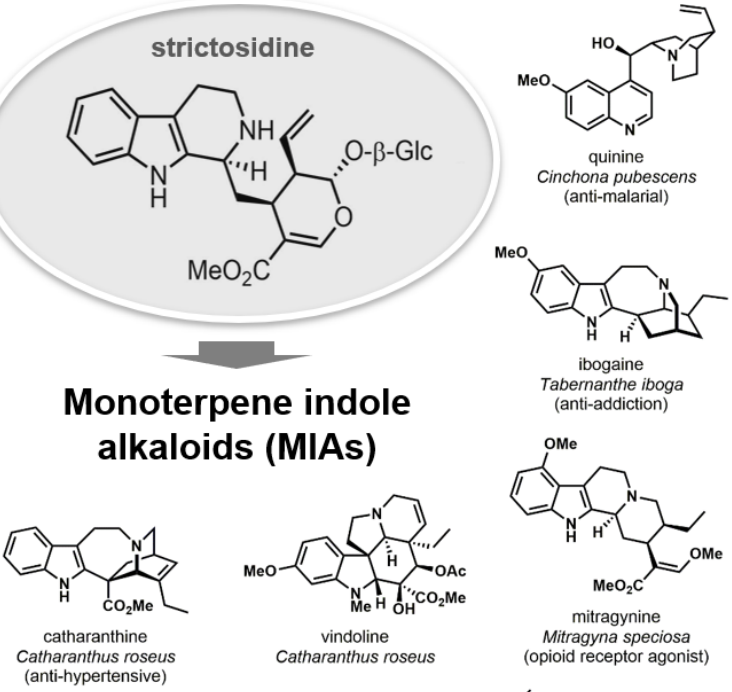
(anti-addiction)
Tabernante
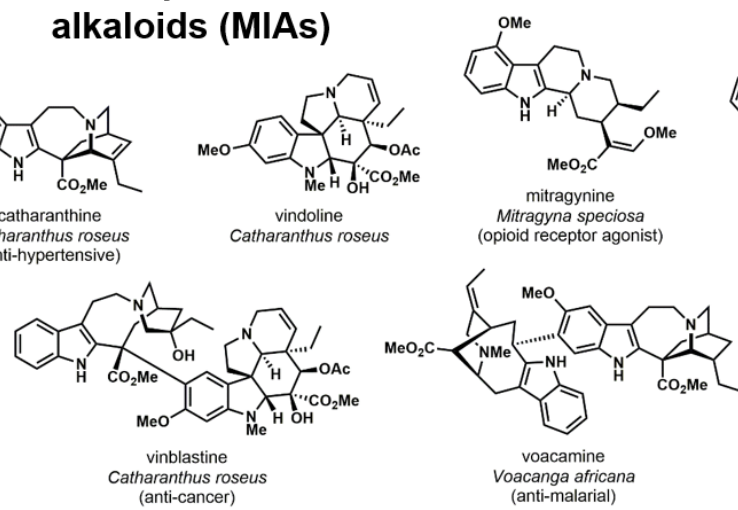
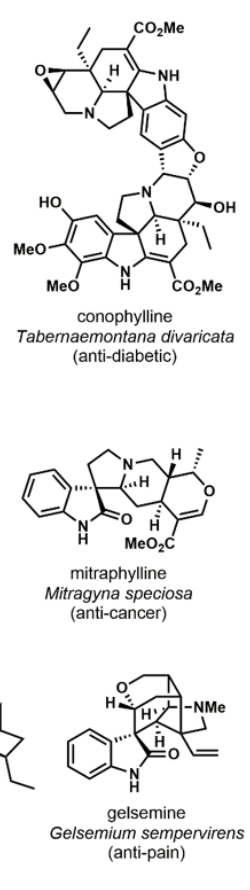

Figure 1. Strictosidine in the last common biosynthetic intermediate for a diverse range of medicinally useful monoterpene indole alkaloids 
bioRxiv preprint doi: https://doi.org/10.1101/2021.08.12.456143; this version posted August 12, 2021. The copyright holder for this preprint

\begin{abstract}
Methods
DNA Assembly. Binary vectors for Agrobacterium tumefaciens-mediated transient expression (agroinfiltration) were assembled using the plant modular cloning toolkit (Engler et al. 2014) and onestep type IIS restriction endonuclease mediated (Golden Gate) assembly protocols as previously described (Cai, Lopez, and Patron 2020). DNA sequences for each pathway enzyme were either synthesised (Twist Bioscience, San Francisco, CA) or amplified from C. roseus cDNA by PCR with overhangs containing Bpil (Bbsl) recognition sites for assembly into pUAP1 (Addgene \#63674). The resulting Level 0 plasmid parts have been domesticated (all endogenous Bpil, Bsal, BsmBI and Sapl recognition sites removed) and are flanked by an inverted pair of Bsal recognition sites that produce overhangs compatible with the phytobrick assembly standard (Patron et al. 2015) (Supplementary Table S1). To create plasmids for transient expression in $N$. benthamiana, Level 0 parts encoding the coding sequence were assembled into Level 1 acceptors in a one-step cloning reaction (Cai, Lopez, and Patron 2020) with Level 0 parts encoding regulatory elements to enable constitutive expression and, when required, a synthetic chloroplast transit peptide sequence (Supplementary Table S2). All plasmids, as well with plasmid maps of their entire sequence, have been submitted to the Addgene repository.

Transient expression in $\boldsymbol{N}$. benthamiana. $N$. benthamiana plants were grown in a controlled environment room with $16 \mathrm{hr}$ light, $8 \mathrm{hr}$ hours dark with room at $22{ }^{\circ} \mathrm{C}, 80 \%$ humidity, and $\sim 200$ $\mu \mathrm{mol} / \mathrm{m}^{2} / \mathrm{s}$ light intensity. A. tumefaciens GV3101 was transformed with the binary plasmid encoding the gene of interest and an individual colony used to inoculate liquid LB medium containing 50 $\mu \mathrm{g} / \mathrm{mL}$ rifampicin, $20 \mu \mathrm{g} / \mathrm{mL}$ gentamicin plus the appropriate antibiotic for maintenance of the binary plasmid (100 $\mu \mathrm{g} / \mathrm{mL}$ carbenicillin, $50 \mu \mathrm{g} / \mathrm{mL}$ kanamycin, or $100 \mu \mathrm{g} / \mathrm{mL}$ spectinomycin). Overnight saturated cultures were centrifuged at 3,400 $\times \mathrm{g}$ for $30 \mathrm{~min}$ at room temperature and cells were resuspended in infiltration medium (10 mM 2-(N-morpholino)ethanesulfonic acid (MES) pH 5.7, 10 $\mathrm{mM} \mathrm{MgCl}_{2}, 200 \mu \mathrm{M}$ 3',5'-Dimethoxy-4'-hydroxyacetophenone (acetosynringone)) and incubated at room temperature for 2-3 hours with slow shaking. All resuspended cultures were diluted to 0.8 $\mathrm{OD}_{600 \mathrm{~nm}}$ and mixed in equal ratios as dictated by the experimental condition. An $A$. tumefaciens strain encoding a gene expressing the P19 suppressor of gene silencing from Tomato Bushy Stunt Virus (TBSV) previously shown to increase heterologous expression was included in every infiltration (Sainsbury, Thuenemann, and Lomonossoff 2009). Healthy plants (29-37 days old) with 3-4 fully expanded true leaves were infiltrated on the abaxial side of the leaf using a $1 \mathrm{~mL}$ needleless syringe and grown for five days in a MLR-352-PE plant growth chamber (Panasonic Healthcare Co, OizumiMachi, Japan) with $16 \mathrm{hr}$ light, $8 \mathrm{hr}$ hours dark at $22^{\circ} \mathrm{C}$ and $120-180 \mu \mathrm{mol} / \mathrm{m}^{2} / \mathrm{s}$ light intensity. All chemical compounds were purchased from Sigma-Aldrich (St. Louis, MO).
\end{abstract}

Metabolite extraction. Five days post-infiltration, $100-300 \mathrm{mg}$ of infiltrated $N$. benthamiana leaf tissue was collected in $1.5 \mathrm{~mL}$ microcentrifuge tubes and flash frozen on liquid nitrogen. Leaf tissue was lyophilised overnight using a VirTis BenchTop SLC freeze dryer (SP Industries, Stone Ridge NY, USA) set to $-49^{\circ} \mathrm{C}$ and 300 mTorr. Samples were then ground to powder using a $3 \mathrm{~mm}$ tungsten carbide bead (Qiagen Cat. No. / ID: 69997) on a TissueLyser II (Qiagen, Hilden, Germany) set to $20 \mathrm{~Hz}$ for $20 \mathrm{sec}$. Lyophilised leaf tissue was extracted with $70 \%$ methanol $+0.1 \%$ formic acid (1:100, w:v). The solvent contained $10 \mu \mathrm{M}$ of harpagoside (Extrasyntheses) as internal standard. The extractions were performed at room temperature for $1 \mathrm{hr}$, with $10 \mathrm{~min}$ sonication and 50 min constant shaking. Samples were centrifuged at 17,000 $\times \mathrm{g}$ for $10 \mathrm{~min}$ to separate the debris and filtered through $0.2 \mu \mathrm{m}$ PTFE disk filters before UPLC/MS analysis.

Metabolite analysis. UPLC/MS analysis was performed on an Impact II qTOF mass spectrometer (Bruker) coupled to an Elute UPLC (Bruker) chromatographic system. Chromatographic separation was carried out on a Phenomenex Kinetex column XB-C18 $(100 \times 2.10 \mathrm{~mm}, 2.6 \mu \mathrm{m}$ particle size $)$ kept at $40{ }^{\circ} \mathrm{C}$ and the binary solvent system consisted of solvent $\mathrm{A}\left(\mathrm{H}_{2} \mathrm{O}+0.1 \%\right.$ formic acid) and solvent B (acetonitrile). Flow rate was $600 \mu \mathrm{L} / \mathrm{min}$. The column was equilibrated with $99 \% \mathrm{~A}$ and $1 \%$ $B$. During the first minute of chromatography, solvent B reached $5 \%$. Then a linear gradient from $5 \%$ $\mathrm{B}$ to $40 \% \mathrm{~B}$ in $5 \mathrm{~min}$ allowed the separation of the compounds of interest. The column was then washed at $100 \% \mathrm{~B}$ for $1.5 \mathrm{~min}$ and re-equilibrated to $1 \% \mathrm{~B}$. Injection volume was $2 \mu \mathrm{L}$.

Mass spectrometry was performed both in positive and negative ion mode with a scan range $\mathrm{m} / \mathrm{z}$ 100-1000. The mass spectrometer was calibrated using sodium formate adducts. The source settings were the following: capillary voltage $3.5 \mathrm{kV}$, nebulizer $2.5 \mathrm{Bar}$, dry gas $11.0 \mathrm{~L} / \mathrm{min}$, dry temperature $250^{\circ} \mathrm{C}$. Data analysis was performed using the Bruker Data Analysis software. 
Quantification of 7-deoxyloganic acid (7-DLA), loganin, loganic acid and strictosidine was based on calibration curves generated using pure compounds. Loganin and loganic acid were purchased from Sigma. 7-deoxyloganic acid was synthesised according to the method previously described (Rodríguez-López et al. 2021). Strictosidine was synthesised and purified as previously described (Stavrinides et al. 2016). The standards were diluted in $70 \%$ methanol $+0.1 \%$ formic acid to give nine calibrants with concentrations between $40 \mathrm{nM}$ and $10 \mu \mathrm{M}$. A linear response was observed for all compounds in this range of concentrations $\left(R^{2}>0.993\right)$.

\section{Results}

\section{MLPL1 from Nepeta mussinii is essential for 7-DLA production in $\mathbf{N}$. benthamiana.}

We transiently expressed pathway enzymes by co-infiltrating $N$. benthamiana with a mixture of $A$. tumefaciens strains with each containing a plasmid encoding a single step of the pathway to produce 7-DLA (Figure 2). To enhance the pool of geraniol pyrophosphate (GPP) substrate from the plastidial 2-C-methyl-D-erythritol 4-phosphate/1-deoxy-D-xylulose 5-phosphate (MEP/DOXP) pathway, we included a bifunctional geranyl/geranylgernayl pyrophosphate synthase (GPPS/GGPPS from Picea abies (Schmidt et al. 2010) also utilised by (Miettinen et al. 2014). In previous experiments, co-expression of 1-deoxy-D-xylulose 5-phosphate synthase (DXS) was shown to aid production of the diterpenoids cembratrien-ol (Brückner and Tissier 2013) and taxadiene (Li et al. 2019). Therefore, to further enhance the pool of isoprenoid substrates, we also expressed DXS from C. roseus. We added a previously characterised synthetic plastid transit peptide (Engler et al. 2014) to the N-terminus of DXS, GPPS and geraniol synthase (GES). We found that the transient expression of DXS, GPPS and GES produces a range of non-volatile glycosylated and oxidised derivates of geraniol (Supplementary Figure S1), consistent with previous studies (Miettinen et al. 2014; Dong et al. 2016).

The biosynthetic pathway for production of cis-trans nepetalactone in the genus Nepeta overlaps the secoiridoid pathway from $C$. roseus up to the stereoselective reduction of 8-oxogeranial to an enol intermediate by the NADPH-dependent iridoid synthase (ISY) (Geu-Flores et al. 2012). It has recently been shown that ISY works in combination with nepetalactol-related short-chain dehydrogenase-reductases (NEPS) and a major latex protein-like enzyme (MLPL) to control of stereospecificity of the ring closure (Lichman et al. 2019; 2020). We therefore hypothesised that addition of the MLPL from Nepeta mussinii (a.k.a Nepeta racemosa), which is specific for the stereochemistry found in strictosidine, would enhance flux through the secoiridoid pathway reconstituted in $\mathrm{N}$. benthamiana

Expression of DXS, GPPS, GES, G8H, 8-hydroxygeraniol oxidoreductase (GOR), ISY, and MLPL further modified the profile of derivatised pathway intermediates (Supplementary Figure S1). Infiltration of the full 7-DLA pathway without MLPL does not produce a peak for 7-DLA (359 $\mathrm{m} / \mathrm{z})$ or acylated 7-DLA (401 m/z) as found in (Miettinen et al. 2014) (Figure 2). However, the inclusion of MLPL produces a clear peak of $359 \mathrm{~m} / z$ which matches the retention time of the 7-DLA standard. Exclusion of 7-deoxyloganetic acid glucosyl transferase (7-DLGT) produces a peak of $359 \mathrm{~m} / \mathrm{z}$ but this does not match the retention time of 7-DLA. It is possible that endogenous glycosyltransferases (GTs) from $N$. benthamiana are able to use 7-deoxyloganetic acid to produce a glucose ester; importantly, the high expression of 7-DLGT compared to endogenous GTs mean that this putative glucose ester peak is not present in the spectra of the full 7-DLA pathway. 


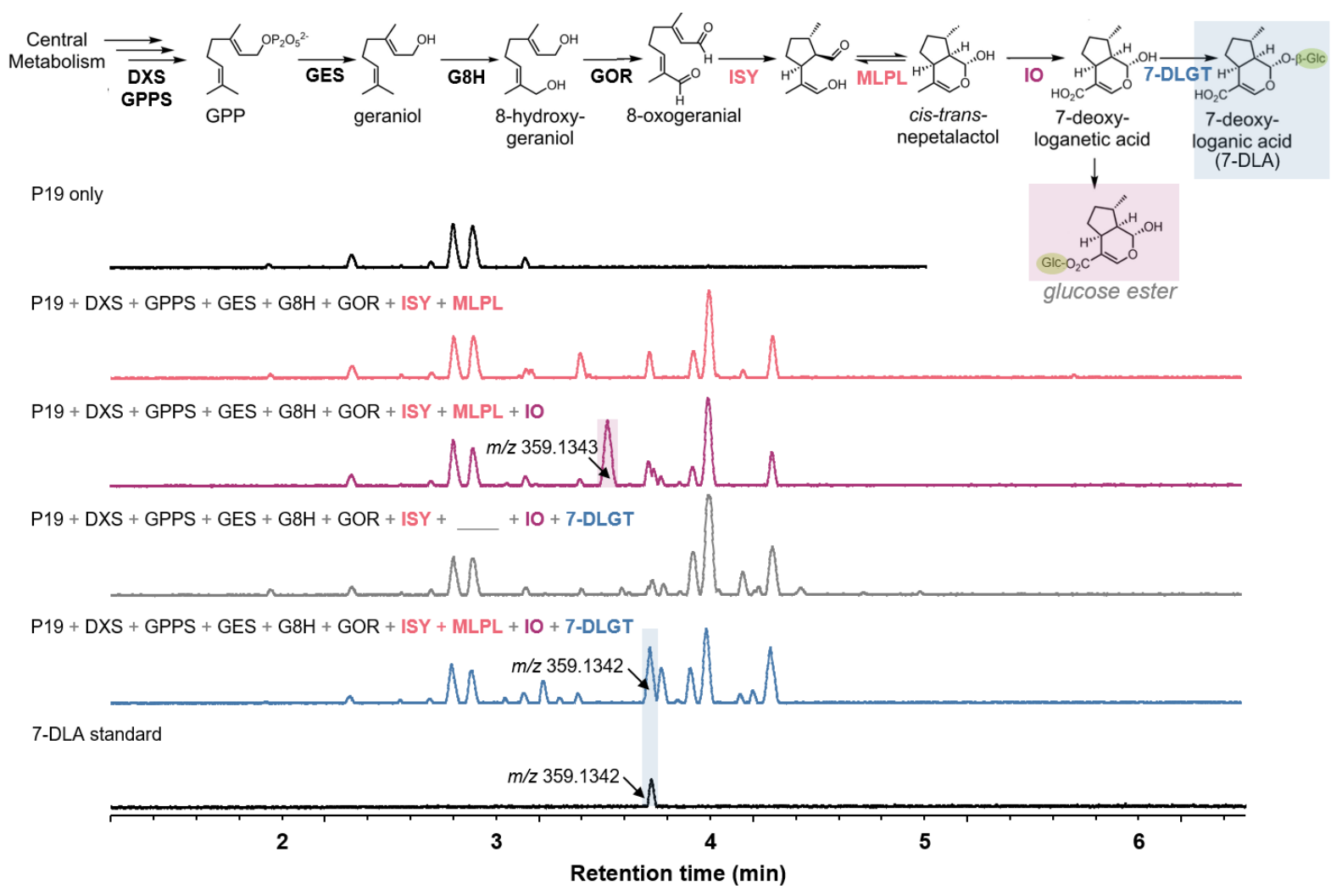

Figure 2. MLPL1 from Nepeta mussinii enables 7-deoxyloganic acid production in $\mathbf{N}$.

benthamiana. Individual strains of $A$. tumefaciens, each containing a plasmid encoding a single pathway enzyme, were mixed in equal ratios and co-infiltrated into $N$. benthamiana leaves. Transient expression of all pathway enzymes plus MLPL produces a peak of $359.13 \mathrm{~m} / \mathrm{z}$ which matches the mass and retention time of a 7-deoxyloganic acid (7-DLA) standard. The reconstituted pathway without DLGT also produces a $359.13 \mathrm{~m} / \mathrm{z}$ peak but at a different retention time, likely due to endogenous glycosyltransferases of $N$. benthamiana producing the glucose ester of 7deoxyloganetic acid. DXS, 1-deoxy-D-xylulose 5-phosphate synthase; GPPS, geranyl diphosphate synthase; GES, geraniol synthase; G8H, geraniol 8-oxidase; GOR, 8-hydroxygeraniol oxidoreductase; ISY, iridoid synthase; MLPL, major latex protein-like; IO, iridoid oxidase; 7-DLGT, 7-deoxyloganetic acid glucosyl transferase

\section{Reconstitution of the complete strictosidine pathway.}

Building on the experimental conditions which produced 7-DLA, we sequentially added the remaining five pathway enzymes and measured the pathway intermediates at each stage (Figure 3A, Supplementary Figure S2-S6). Co-infiltration of strains expressing enzymes for the entire pathway produces a distinct peak at $531 \mathrm{~m} / \mathrm{z}$ matching the strictosidine standard (Figure 3C, Supplementary Figure S5); this pathway configuration produces $4.29 \pm 2.00 \mu \mathrm{M}$ of strictosidine which correlates to $0.23 \pm 0.11 \mathrm{mg}$ strictosidine / g dry weight leaf tissue $(0.023 \% \mathrm{DW})$. The accumulation of loganin suggests secologanin synthase is a bottleneck step. This is in contrast to previous data suggesting that loganic acid O-methyltransferase (LAMT), which has a low substrate affinity $\left(K_{m}=12.5-14.8 \mathrm{mM}\right)$ (Madyastha et al. 1973; Murata et al. 2008), might be a rate-limiting step of the late stages of the secoiridoid pathway. In addition to the substantial peak corresponding to strictosidine, transient expression of the full pathway also produces a smaller peak (Figure $\mathbf{3 C}$, Supplementary Figure S6) with a mass shift of 86 Da from strictosidine, suggesting that this may be a malonylated derivative of strictosidine produced by endogenous $N$. benthamiana acyltransferases.

Transient expression of the strictosidine pathway without DXS, GPPS, and MLPL (Figure 3B) confirms the beneficial effect of these enzymes. Addition of MLPL increases strictosidine production $>60$ fold while supplementation of GPPS improves yield $\sim 5$ fold. DXS supplementation did not change the amount of strictosidine produced, however, it does produce additional derivatives of geraniol (Supplementary Figure S1). 
A
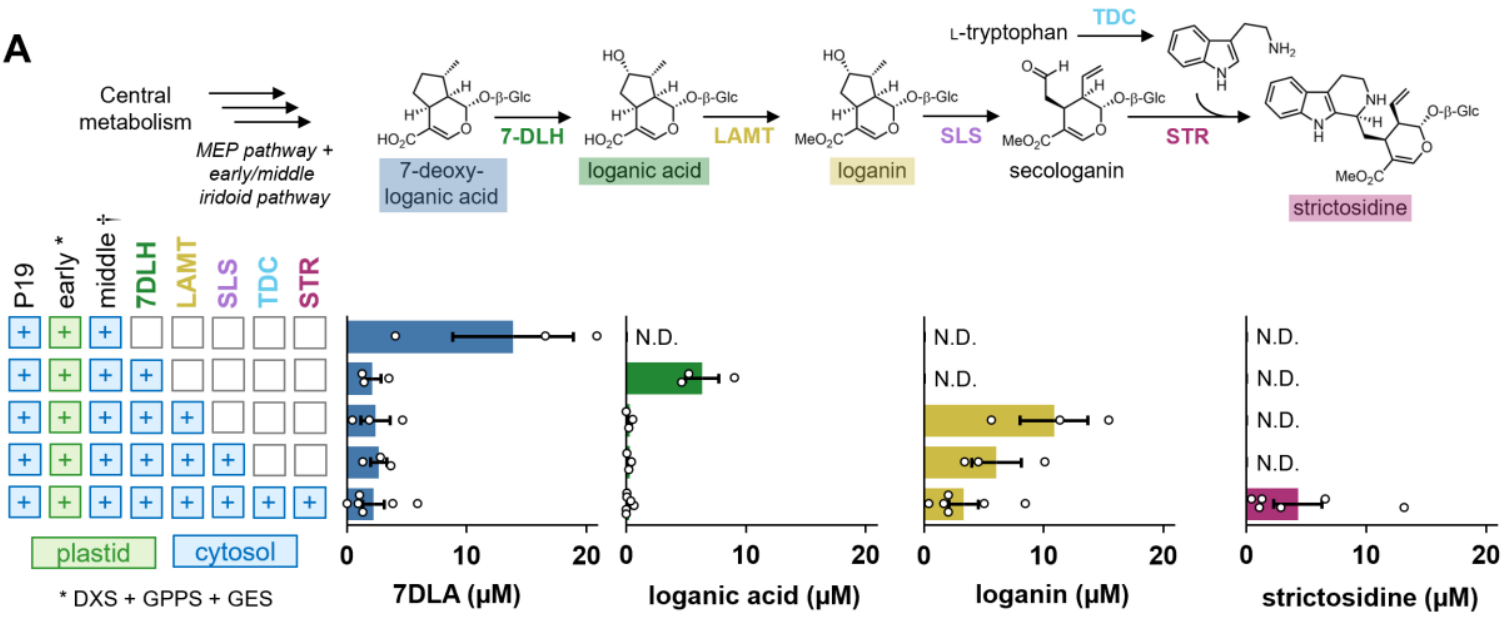

* DXS + GPPS + GES

7DLA $(\mu \mathrm{M})$

loganic acid $(\mu \mathrm{M})$

loganin $(\mu \mathrm{M})$

strictosidine $(\mu \mathrm{M})$

B

$M L P L+10+7-D L G T$

C [ TIC strictosidine malonyl-
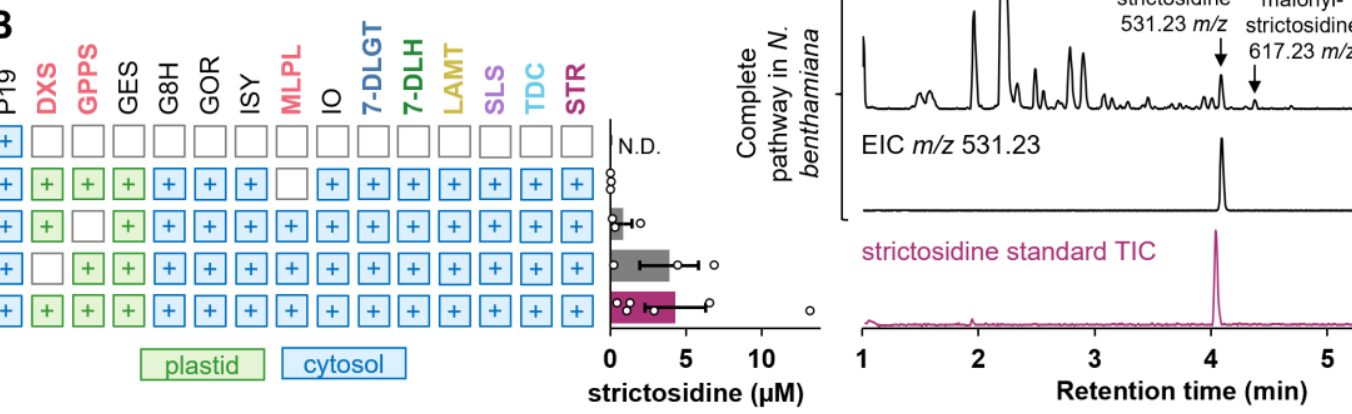
$617.23 \mathrm{~m} / \mathrm{z}$ EIC $\mathrm{m} / \mathrm{z} 531.23$ Quantification of intermediates and final product strictosidine by UPLC/MS analysis. (B) Absence of MLPL reduces strictosidine production $>60$ fold while supplementation of GPPS improves yield $\sim 5$ fold. (C) the total ion chromatogram of leaf tissue infiltrated with entire pathway to strictosidine (including DXS, GPPS, and MLPL). The peak at 4.09 min retention time in the TIC and extracted ion chromatogram at $531.23 \mathrm{~m} / \mathrm{z}$ matches a strictosidine standard. N.D., not detected; 7-DLH, 7deoxyloganic acid hydroxylase; LAMT, loganic acid O-methyltransferase; SLS, secologanin synthase; TDC, tryptophan decarboxylase; STR, strictosidine synthase. Values and error bars represent the mean and the standard error of $n=3$ or $n=6$ biological independent leaf samples.

\section{Mimicking $C$. roseus subcellular compartmentalisation maximises strictosidine production.}

To compare the effect of chloroplast and cytosolic enzyme localisation on yields of 7-DLA and strictosidine production, we added (or removed in the case of GPPS/GES) a transit peptide to each enzyme (Figure 4). To enhance flux of isoprenoid precursors in the cytosol, we aimed to alleviate the rate limiting step of the mevalonate pathway by co-infiltrating a truncated 3-hydroxy-3methylglutaryl-coenzyme A reductase (tHMGR) from oat, previously shown to improve titres of the triterpenoid $\beta$-amyrin in $N$. benthamiana (Reed et al. 2017). When all enzymes are localised to the cytosol, flux through the secoiridoid pathway is minimal ( 90-fold reduction for 7-DLA) while localisation of all pathway enzymes to the chloroplast results in 5-fold less 7-DLA (Figure 4A). The best yields of 7-DLA (Figure 4A) and strictosidine (Figure 4B) were obtained with chloroplast localisation of the early pathway and cytosolic localisation of subsequent steps. Production of 7-DLA in the chloroplast is possibly limited by the availability of partner P450 reductases for $\mathrm{G} 8 \mathrm{H}$ and iridoid oxidase (IO) or small molecule substrates such as UDP-glucose for 7-DLGT, however, all possible divisions of pathway enzymes between the cytosol and chloroplast still produce 7-DLA indicating that pathway intermediates can cross the chloroplast membrane. 
A

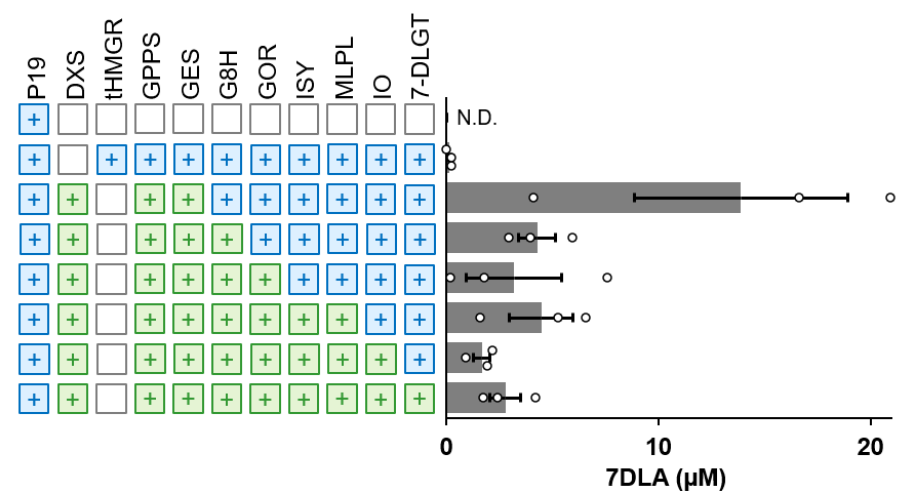

B

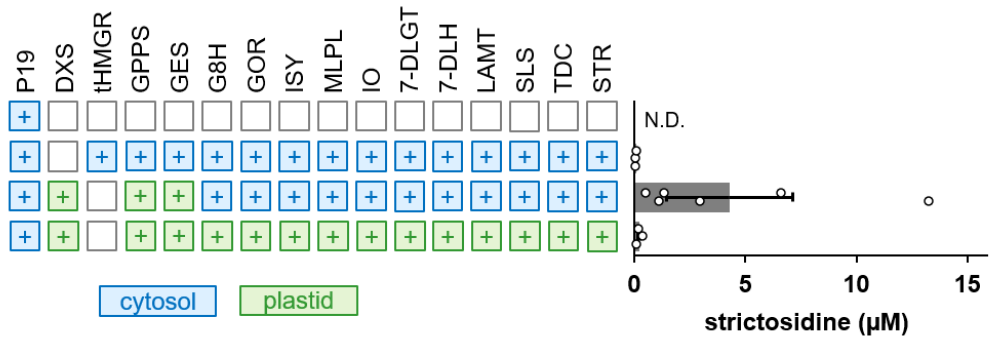

Figure 4. Relocation of 7-DLA (A) and strictosidine (B) biosynthesis genes to the cytosol (blue) or the chloroplast (green) decreases product yield. tHMGR, truncated 3-hydroxy-3methylglutaryl-coenzyme A reductase. Values and error bars represent the mean and the standard error of $n=3$ or $n=6$ biological independent leaf samples.

\section{Discussion}

In this work, we provide the first report of high quantities of strictosidine $(0.23 \pm 0.11 \mathrm{mg} / \mathrm{g} \mathrm{DW})$ produced from central metabolism in a photosynthetic organism. Plants from the mint family (Lamiaceae) produce a range of iridoid products (Boachon et al. 2018); the genus Nepeta L., colloquially known as catnip or catmint, use the early part of the secoiridoid pathway to produce nepetalactones for insect defence which are also responsible for the euphoric effects on cats. Recent work revealed that NEPS controls the stereospecificity of the ring closure (Lichman et al. 2019) and that production of cis-trans nepetalactol is assisted by MLPL (Lichman et al. 2020). The heterologous expression of MLPL from $N$. mussinii to assist with cyclisation of the reactive enol product of ISY overcame bottlenecks in the secoiridoid pathway (Figure 2) and was critical for enabling heterologous production of strictosidine in $N$. benthamiana (Figure 3 ). We hypothesise that MLPL might similarly enhance secoiridoid metabolic engineering in microorganisms such as yeast (Brown et al. 2015). Indeed, a cell-free in vitro one-pot enzyme cascade included MLPL with nine other pathway enzymes, accessory proteins, and cofactor regeneration enzymes to produce $\sim 1 \mathrm{~g} / \mathrm{L}$ nepetalactone (Bat-Erdene et al. 2021).

The MIA pathway in $C$. roseus is highly compartmentalised across both sub-cellular compartments and cell types. The first committed step is geraniol synthesis (GES), which is localised to the chloroplast of internal phloem-associated parenchyma (IPAP) cells (Simkin et al. 2013). To increase substrate availability for GES, we co-expressed GPPS from $P$. abies and DXS from $C$. roseus. Expression of chloroplast-targeted PaGPPS improved yield $\sim 5$ fold (Figure 3) in similarity with previously reported effects on the production of geraniol (Dong et al. 2016). Of note, PaGPPS is nearly identical (Supplementary Figure S7) to a GPPS from Picea glauca shown in vitro to produce higher levels of the monoterpene limonene relative to six other GPPS sequences commonly used in terpene metabolic engineering (Dudley et al. 2020). Interestingly, DXS had relatively little effect on the yield of strictosidine in contrast to previously reported effects on the production of diterpenoids (Brückner and Tissier 2013; Li et al. 2019).

Recent efforts to engineer metabolic pathways have found benefits in altering the compartmentalisation of pathway enzymes (Jensen and Scharff 2019; Dong et al. 2016). For example, the pathway to produce the cyanogenic glucoside dhurrin was relocated to the chloroplast of Nicotiana tabacum where ferredoxin, reduced via the photosynthetic electron transport chain, can 
bioRxiv preprint doi: https://doi.org/10.1101/2021.08.12.456143; this version posted August 12, 2021. The copyright holder for this preprint made available under aCC-BY-NC 4.0 International license.

serves as an efficient electron donor to the two cytochromeP450s (CYPs) within the pathway (Gnanasekaran et al. 2016). Additionally, the localisation of enzymes encoding the late steps of the artemisinin pathway to the chloroplast in $N$. tabacum produced higher levels of artemisinin $(800 \mu \mathrm{g} / \mathrm{g}$ DW) (Malhotra et al. 2016) and artemisinic acid ( 1200 $\mu \mathrm{g} / \mathrm{g} \mathrm{DW})$ (Fuentes et al. 2016) compared to localisation within the cytosol $(6.8 \mu \mathrm{g} / \mathrm{g}$ DW artemisinin) (Farhi et al. 2011). This increase is possibly due to the isolation of metabolites from the cytosol where they may both impact viability and be exposed to unwanted derivatisation by endogenous glycosyltransferases (van Herpen et al. 2010; Ting et al. 2013; B. Wang et al. 2016). Production of halogenated indican (Fräbel et al. 2018) and vanillin (Gallage et al. 2018) in N. benthmaiana also benefited from chloroplast localisation. In contrast, a recent report found that production of diterpenoids (typically synthesised in the chloroplast) was dramatically enhanced by co-opting the cytosolic mevalonate pathway to produce GGPP rather than the chloroplast MEP pathway (De La Peña and Sattely 2021).

In this study, we found that the optimal configuration for reconstruing the pathway to strictosidine within $N$. benthamiana leaves is to match the $C$. roseus strategy of utilising the chloroplast MEP pathway for isoprenoid precursors to produce geraniol and then localising the remaining pathway enzymes in the cytosol (Figure 4). We hypothesise that monoterpene production in the cytosol is limited since GPP (10 carbons) produced by GPPS is also the substrate for the $N$. benthamiana farnesylpyrophosphate synthase (FPPS), which produces farnesylpyrophosphate (FPP) (15 carbons). Supporting this hypothesis is data suggesting that all four copies of NbFPPS are upregulated to produce sesquiterpenoid phytosterols and phytoalexins in response to Phytophthora infestans (Rin et al. 2020). A. tumefaciens also elicits widespread transcriptional remodelling when infiltrated into $N$. benthamiana (Grosse-Holz et al. 2018). This competition between GES and FPPS might also explain the higher levels of geraniol and geraniol derivatives in the plastid reported by (Dong et al. 2016). Future efforts to conditionally inactivate NbFPPS during heterologous production might enable a metabolic engineering strategy that could take advantage of both the plastid and cytosolic route to geraniol production.

In C. roseus, geraniol diffuses (or is transported) from the plastid into the cytosol to react with $\mathrm{G} 8 \mathrm{H}$ bound to the exterior of the ER membrane. The next steps (G8H to deoxyloganic acid hydroxylase (7-DLH)) are active in the cytosol of IPAP cells with two CYPs (G8H and IO) anchored to the ER membrane (Miettinen et al. 2014). Loganic acid is then transported by NPF2.4/5/6 (Larsen et al. 2017) to epidermal cells where four more enzymes (LAMT to strictosidine synthase (STR)) produce strictosidine (Yamamoto et al. 2016; 2019). Strictosidine accumulates in the vacuole with export mediated by NPF2.9 (Payne et al. 2017). Thus, four pathway CYPs (G8H, IO, 7-DLH and secologanin synthase (SLS)) are likely interfacing with endogenous $N$. benthamiana CYP reductases for electron transfer of NADPH to the CYPs. It is possible that the necessary CYP reductases are less abundant in the chloroplast and thus limit the accumulation of strictosidine in this compartment. It is also possible that the CYP450s are improperly membrane anchored or that higher stromal $\mathrm{pH}$ of the chloroplast ( 8.0)(Song et al. 2004) inhibits enzyme activity compared to the cytosol ( $\mathrm{pH} \sim 7.0)$. We also considered if lack of an additional cofactor for LAMT, S-Adenosyl methionine (SAM) explains the low levels of strictosidine production (relative to 7-DLA) in the chloroplast. However, this small molecule is known to be actively transported into the plastid (Linka and Weber 2010) and is an essential substrate for ChIM (Mg-protoporphyrin IX methyltransferase) involved in chlorophyll biosynthesis within the chloroplast.

The production of strictosidine in planta opens up a wealth of MIA products to biological synthesis. Particularly as new biosynthesis pathways for additional MIAs are discovered (e.g. the anti-addictive compound ibogaine (Farrow et al. 2019), the antimalarial quinine (Trenti et al. 2021)), the possibility of coupling this work in a plug-and-play manner with downstream biosynthesis modules is an exciting prospect for natural product synthesis.

\section{Supplementary data}

Supplementary Figure S1. Early metabolites of the iridoid pathway are derivatised by endogenous enzymes from $N$. benthamiana.

Supplementary Figure S2. Detection of 7-deoxyloganic acid by transient expression in $N$. benthamiana

Supplementary Figure S3. Detection of loganic acid by transient expression in $N$. benthamiana

Supplementary Figure S4. Detection of loganin by transient expression in $N$. benthamiana

Supplementary Figure S5. Detection of strictosidine by transient expression in $N$. benthamiana 
Supplementary Figure S6. Detection of malonyl-strictosidine by transient expression in $N$. benthamiana

Supplementary Figure S7. Amino acid sequence alignment of candidate GPPS enzymes

Supplemental Table S1. Enzymes and L0 plasmid parts built in this study

Supplemental Table S2. Level 1 plasmids for A. tumefaciens - mediated transient expression in $\mathrm{N}$. benthamiana

\section{Author Contributions}

Q.M.D., S.E.O., L.C, and N.J.P. conceived the study. Q.M.D performed DNA assembly and transient expression with assistance from S.J., D.A.S.G and L.C. performed metabolite extraction and analysis. Q.M.D., S.E.O., N.J.P., and L.C. wrote the manuscript. S.E.O. and N.J.P obtained funding and provided supervision.

\section{ORCID}

Quentin M. Dudley (0000-0002-2987-5172)

Seohyun Jo (0000-0001-5742-2376)

Sarah E. O'Connor (0000-0003-0356-6213)

Lorenzo Caputi (0000-0002-7783-6733)

Nicola J. Patron (0000-0002-8389-1851)

\section{Acknowledgements}

We thank Nat Sherden for help with plasmid construction and Benjamin Lichman for guidance working with MLPL. pLO-AstHMGR was a generous gift from Anne Osbourn.

\section{Data Availability}

Plasmids will be available from Addgene (submission in progress).

\section{Funding}

The authors gratefully acknowledge the support of the Biotechnology and Biological Sciences Research Council (BBSRC). This research was funded by the BBSRC Strategic Programme Grant 'Genomes to Food Security' (BB/CSP1720/1) and an industrial partnership award with Leaf Expression Systems (BB/P010490/1). The funders had no role in study design, data collection and analysis, decision to publish, or preparation of the manuscript.

\section{Conflict of interest statement}

None declared

\section{$\underline{\text { References }}$}

Bally, Julia, Hyungtaek Jung, Cara Mortimer, Fatima Naim, Joshua G. Philips, Roger Hellens, Aureliano Bombarely, Michael M. Goodin, and Peter M. Waterhouse. 2018. "The Rise and Rise of Nicotiana Benthamiana: A Plant for All Reasons." Annual Review of Phytopathology 56: 405-26. https://doi.org/10.1146/annurev-phyto-080417-050141.

Bat-Erdene, Undramaa, John M Billingsley, William C Turner, Benjamin R Lichman, Francesca M Ippoliti, Neil K Garg, Sarah E O'Connor, and Yi Tang. 2021. "Cell-Free Total Biosynthesis of Plant Terpene Natural Products Using an Orthogonal Cofactor Regeneration System." ACS Catalysis 11: 9898-9903. https://doi.org/10.1021/acscatal.1c02267.

Billingsley, John M., Anthony B. DeNicola, Joyann S. Barber, Man Cheng Tang, Joe Horecka, Angela Chu, Neil K. Garg, and Yi Tang. 2017. "Engineering the Biocatalytic Selectivity of Iridoid Production in Saccharomyces Cerevisiae." Metabolic Engineering 44 (August): 117-25. https://doi.org/10.1016/j.ymben.2017.09.006.

Boachon, Benoît, C. Robin Buell, Emily Crisovan, Natalia Dudareva, Nicolas Garcia, Grant Godden, Laura Henry, et al. 2018. "Phylogenomic Mining of the Mints Reveals Multiple Mechanisms Contributing to the Evolution of Chemical Diversity in Lamiaceae." Molecular Plant 11 (8): 1084-96. https://doi.org/10.1016/j.molp.2018.06.002.

Brown, Stephanie, Marc Clastre, Vincent Courdavault, and Sarah E. O'Connor. 2015. "De Novo Production of the Plant-Derived Alkaloid Strictosidine in Yeast." Proceedings of the National Academy of Sciences of the United States of America 112 (11): 3205-10. https://doi.org/10.1073/pnas.1423555112.

Brückner, Kathleen, and Alain Tissier. 2013. "High-Level Diterpene Production by Transient 
Expression in Nicotiana Benthamiana." Plant Methods 9 (46).

Cai, Yao-Min, Jose A. Carrasco Lopez, and Nicola J. Patron. 2020. "Phytobricks: Manual and Automated Assembly of Constructs for Engineering Plants." In DNA Cloning and Assembly, edited by Sunila Chandaran and Kevin W. George, 179-99. New York, NY: Humana. http://link.springer.com/10.1007/978-1-62703-764-8.

Caputi, Lorenzo, Jakob Franke, Scott C. Farrow, Khoa Chung, Richard M.E. Payne, Trinh Don Nguyen, Thu Thuy T. Dang, et al. 2018. "Missing Enzymes in the Biosynthesis of the Anticancer Drug Vinblastine in Madagascar Periwinkle." Science 360 (6394): 1235-39. https://doi.org/10.1126/science.aat4100.

Dong, Lemeng, Esmer Jongedijk, Harro Bouwmeester, and Alexander Van Der Krol. 2016. "Monoterpene Biosynthesis Potential of Plant Subcellular Compartments." New Phytologist 209 (2): 679-90. https://doi.org/10.1111/nph.13629.

Dudley, Quentin M., Ashty S. Karim, Connor J. Nash, and Michael C. Jewett. 2020. "In Vitro Prototyping of Limonene Biosynthesis Using Cell-Free Protein Synthesis." Metabolic Engineering 61 (May): 251-60. https://doi.org/10.1016/j.ymben.2020.05.006.

Engler, Carola, Mark Youles, Ramona Gruetzner, Tim Martin Ehnert, Stefan Werner, Jonathan D.G. Jones, Nicola J. Patron, and Sylvestre Marillonnet. 2014. "A Golden Gate Modular Cloning Toolbox for Plants." ACS Synthetic Biology 3 (11): 839-43. https://doi.org/10.1021/sb4001504.

Farhi, Moran, Elena Marhevka, Julius Ben-Ari, Anna Algamas-Dimantov, Zhuobin Liang, Vardit Zeevi, Orit Edelbaum, et al. 2011. "Generation of the Potent Anti-Malarial Drug Artemisinin in Tobacco." Nature Biotechnology 29 (12): 1072-74. https://doi.org/10.1038/nbt.2054.

Farrow, Scott C., Mohamed O. Kamileen, Lorenzo Caputi, Kate Bussey, Julia E.A. Mundy, Rory C. McAtee, Corey R.J. Stephenson, and Sarah E. O'Connor. 2019. "Biosynthesis of an AntiAddiction Agent from the Iboga Plant." Journal of the American Chemical Society 141 (33): 12979-83. https://doi.org/10.1021/jacs.9b05999.

Fräbel, Sabine, Bastian Wagner, Markus Krischke, Volker Schmidts, Christina M. Thiele, Agata Staniek, and Heribert Warzecha. 2018. "Engineering of New-to-Nature Halogenated Indigo Precursors in Plants." Metabolic Engineering 46 (December 2017): 20-27. https://doi.org/10.1016/j.ymben.2018.02.003.

Fuentes, Paulina, Fei Zhou, Alexander Erban, Daniel Karcher, Joachim Kopka, and Ralph Bock. 2016. "A New Synthetic Biology Approach Allows Transfer of an Entire Metabolic Pathway from a Medicinal Plant to a Biomass Crop." ELife 5: e13664. https://doi.org/10.7554/eLife.13664.

Gallage, Nethaji J., Kirsten Jørgensen, Christian Janfelt, Agnieszka J.Z. Nielsen, Thomas Naake, Eryk Duński, Lene Dalsten, Michel Grisoni, and Birger Lindberg Møller. 2018. "The Intracellular Localization of the Vanillin Biosynthetic Machinery in Pods of Vanilla Planifolia." Plant and Cell Physiology 59 (2): 304-18. https://doi.org/10.1093/pcp/pcx185.

Geu-Flores, Fernando, Nathaniel H. Sherden, Vincent Courdavault, Vincent Burlat, Weslee S. Glenn, Cen Wu, Ezekiel Nims, Yuehua Cui, and Sarah E. O'Connor. 2012. "An Alternative Route to Cyclic Terpenes by Reductive Cyclization in Iridoid Biosynthesis." Nature 492 (7427): 138-42. https://doi.org/10.1038/nature11692.

Gnanasekaran, Thiyagarajan, Daniel Karcher, Agnieszka Zygadlo Nielsen, Helle Juel Martens, Stephanie Ruf, Xenia Kroop, Carl Erik Olsen, et al. 2016. "Transfer of the Cytochrome P450Dependent Dhurrin Pathway from Sorghum Bicolor into Nicotiana Tabacum Chloroplasts for Light-Driven Synthesis." Journal of Experimental Botany 67 (8): 2495-2506. https://doi.org/10.1093/jxb/erw067.

Goodin, Michael M., David Zaitlin, Rayapati A. Naidu, and Steven A. Lommel. 2008. "Nicotiana Benthamiana: Its History and Future as a Model for Plant-Pathogen Interactions." Molecular Plant-Microbe Interactions 21 (8): 1015-26. https://doi.org/10.1094/MPMI-21-8-1015.

Grosse-Holz, Friederike, Steven Kelly, Svenja Blaskowski, Farnusch Kaschani, Markus Kaiser, and Renier A.L. van der Hoorn. 2018. "The Transcriptome, Extracellular Proteome and Active Secretome of Agroinfiltrated Nicotiana Benthamiana Uncover a Large, Diverse Protease Repertoire." Plant Biotechnology Journal 16 (5): 1068-84. https://doi.org/10.1111/pbi.12852.

Heijden, Robert van Der, Denise I Jacobs, Wim Snoeijer, Didier Hallard, and Robert Verpoorte. 2004. "The Catharanthus Alkaloids: Pharmacognosy and Biotechnology." Current Medicinal Chemistry 11 (5): 607-28. https://doi.org/10.2174/0929867043455846.

Herpen, Teun W.J.M. van, Katarina Cankar, Marilise Nogueira, Dirk Bosch, Harro J. Bouwmeester, and Jules Beekwilder. 2010. "Nicotiana Benthamiana as a Production Platform for Artemisinin Precursors." PLOS ONE 5 (12). https://doi.org/10.1371/journal.pone.0014222.

Ishikawa, Hayato, David A. Colby, Shigeki Seto, Porino Va, Annie Tam, Hiroyuki Kakei, Thomas J. Rayl, Inkyu Hwang, and Dale L. Boger. 2009. "Total Synthesis of Vinblastine, Vincristine, 
Related Natural Products, and Key Structural Analogues." Journal of the American Chemical Society 131 (13): 4904-16. https://doi.org/10.1021/ja809842b.

Jensen, Poul Erik, and Lars B. Scharff. 2019. "Engineering of Plastids to Optimize the Production of High-Value Metabolites and Proteins." Current Opinion in Biotechnology 59: 8-15. https://doi.org/10.1016/j.copbio.2019.01.009.

Kuboyama, Takeshi, Satoshi Yokoshima, Hidetoshi Tokuyama, and Tohru Fukuyama. 2004. "Stereocontrolled Total Synthesis of (+)-Vincristine." Proceedings of the National Academy of Sciences 101 (33): 11966-70. https://doi.org/10.1016/j.tetasy.2008.12.020.

La Peña, Ricardo De, and Elizabeth S. Sattely. 2021. "Rerouting Plant Terpene Biosynthesis Enables Momilactone Pathway Elucidation." Nature Chemical Biology 17 (2): 205-12. https://doi.org/10.1038/s41589-020-00669-3.

Larsen, Bo, Victoria L. Fuller, Jacob Pollier, Alex Van Moerkercke, Fabian Schweizer, Richard Payne, Maite Colinas, Sarah E. O'Connor, Alain Goossens, and Barbara A. Halkier. 2017. "Identification of Iridoid Glucoside Transporters in Catharanthus Roseus." Plant and Cell Physiology 58 (9): 1507-18. https://doi.org/10.1093/pcp/pcx097.

Li, Jianhua, Ishmael Mutanda, Kaibo Wang, Lei Yang, Jiawei Wang, and Yong Wang. 2019. "Chloroplastic Metabolic Engineering Coupled with Isoprenoid Pool Enhancement for Committed Taxanes Biosynthesis in Nicotiana Benthamiana." Nature Communications 10 (1): 1-12. https://doi.org/10.1038/s41467-019-12879-y.

Lichman, Benjamin R., Grant T. Godden, John P. Hamilton, Lira Palmer, Mohamed O. Kamileen, Dongyan Zhao, Brieanne Vaillancourt, et al. 2020. "The Evolutionary Origins of the Cat Attractant Nepetalactone in Catnip." Science Advances 6 (20). https://doi.org/10.1126/sciadv.aba0721.

Lichman, Benjamin R., Mohamed O. Kamileen, Gabriel R. Titchiner, Gerhard Saalbach, Clare E.M. Stevenson, David M. Lawson, and Sarah E. O'Connor. 2019. "Uncoupled Activation and Cyclization in Catmint Reductive Terpenoid Biosynthesis." Nature Chemical Biology 15 (1): $71-$ 79. https://doi.org/10.1038/s41589-018-0185-2.

Linka, Nicole, and Andreas P.M. Weber. 2010. "Intracellular Metabolite Transporters in Plants." Molecular Plant 3 (1): 21-53. https://doi.org/10.1093/mp/ssp108.

Lomonossoff, George P., and Marc André D’Aoust. 2016. "Plant-Produced Biopharmaceuticals: A Case of Technical Developments Driving Clinical Deployment." Science 353 (6305): 1237-40. https://doi.org/10.1126/science.aaf6638.

Madyastha, K. Madhava., Rocco. Guarnaccia, Claire. Baxter, and Carmine. J. Coscia. 1973. "SAdenosyl-L-Methionine: Loganic Acid Methyltransferase. A Carboxyl-Alkylating Enzyme from Vinca Rosea." Journal of Biological Chemistry 248 (7): 2497-2501. https://doi.org/10.1016/S0021-9258(19)44136-7.

Malhotra, Karan, Mayavan Subramaniyan, Khushboo Rawat, Md Kalamuddin, M. Irfan Qureshi, Pawan Malhotra, Asif Mohmmed, Katrina Cornish, Henry Daniell, and Shashi Kumar. 2016. "Compartmentalized Metabolic Engineering for Artemisinin Biosynthesis and Effective Malaria Treatment by Oral Delivery of Plant Cells." Molecular Plant 9 (11): 1464-77. https://doi.org/10.1016/j.molp.2016.09.013.

Miettinen, Karel, Lemeng Dong, Nicolas Navrot, Thomas Schneider, Vincent Burlat, Jacob Pollier, Lotte Woittiez, et al. 2014. "The Seco-Iridoid Pathway from Catharanthus Roseus." Nature Communications 5 (3606). https://doi.org/10.1038/ncomms4606.

Murata, Jun, Jonathon Roepke, Heather Gordon, and Vincenzo De Luca. 2008. "The Leaf Epidermome of Catharanthus Roseus Reveals Its Biochemical Specialization." Plant Cell 20 (3): 524-42. https://doi.org/10.1105/tpc.107.056630.

Pan, Qifang, Natali Rianika Mustafa, Kexuan Tang, Young Hae Choi, and Robert Verpoorte. 2016. "Monoterpenoid Indole Alkaloids Biosynthesis and Its Regulation in Catharanthus Roseus: A Literature Review from Genes to Metabolites." Phytochemistry Reviews 15 (2): 221-50. https://doi.org/10.1007/s11101-015-9406-4.

Patron, Nicola J. 2020. "Beyond Natural: Synthetic Expansions of Botanical Form and Function." New Phytologist 227 (2): 295-310. https://doi.org/10.1111/nph.16562.

Patron, Nicola J., Diego Orzaez, Sylvestre Marillonnet, Heribert Warzecha, Colette Matthewman, Mark Youles, Oleg Raitskin, et al. 2015. "Standards for Plant Synthetic Biology: A Common Syntax for Exchange of DNA Parts." New Phytologist 208: 13-19.

Payne, Richard M.E., Deyang Xu, Emilien Foureau, Marta Ines Soares Teto Carqueijeiro, Audrey Oudin, Thomas Dugé De Bernonville, Vlastimil Novak, et al. 2017. "An NPF Transporter Exports a Central Monoterpene Indole Alkaloid Intermediate from the Vacuole." Nature Plants 3 (January): 1-9. https://doi.org/10.1038/nplants.2016.208. 
bioRxiv preprint doi: https://doi.org/10.1101/2021.08.12.456143; this version posted August 12, 2021. The copyright holder for this preprint

Qu, Yang, Michael E.A.M. Easson, Razvan Simionescu, Josef Hajicek, Antje M.K. Thamm, Vonny Salim, and Vincenzo De Luca. 2018. "Solution of the Multistep Pathway for Assembly of Corynanthean, Strychnos, Iboga, and Aspidosperma Monoterpenoid Indole Alkaloids from 19EGeissoschizine." Proceedings of the National Academy of Sciences of the United States of America 115 (12): 3180-85. https://doi.org/10.1073/pnas.1719979115.

Reed, James, Michael J. Stephenson, Karel Miettinen, Bastiaan Brouwer, Aymeric Leveau, Paul Brett, Rebecca J.M. Goss, Alain Goossens, Maria A. O'Connell, and Anne Osbourn. 2017. “A Translational Synthetic Biology Platform for Rapid Access to Gram-Scale Quantities of Novel Drug-like Molecules." Metabolic Engineering 42: 185-93. https://doi.org/10.1016/j.ymben.2017.06.012.

Rin, Soriya, Sayaka Imano, Maurizio Camagna, Takamasa Suzuki, Aiko Tanaka, Ikuo Sato, Sotaro Chiba, Kazuhito Kawakita, and Daigo Takemoto. 2020. "Expression Profiles of Genes for Enzymes Involved in Capsidiol Production in Nicotiana Benthamiana." Journal of General Plant Pathology 86 (5): 340-49. https://doi.org/10.1007/s10327-020-00931-5.

Rodríguez-López, Carlos E., Benke Hong, Christian Paetz, Yoko Nakamura, Konstantinos Koudounas, Valentina Passeri, Luciana Baldoni, Fiammetta Alagna, Ornella Calderini, and Sarah E. O'Connor. 2021. “Two Bi-Functional Cytochrome P450 CYP72 Enzymes from Olive (Olea Europaea) Catalyze the Oxidative C-C Bond Cleavage in the Biosynthesis of SecoxyIridoids - Flavor and Quality Determinants in Olive Oil." New Phytologist 229 (4): 2288-2301. https://doi.org/10.1111/nph.16975.

Saiman, Mohd Zuwairi, Karel Miettinen, Natali Rianika Mustafa, Young Hae Choi, Robert Verpoorte, and Anna Elisabeth Schulte. 2018. "Metabolic Alteration of Catharanthus Roseus Cell Suspension Cultures Overexpressing Geraniol Synthase in the Plastids or Cytosol." Plant Cell, Tissue and Organ Culture 134 (1): 41-53. https://doi.org/10.1007/s11240-018-1398-5.

Sainsbury, Frank, Eva C. Thuenemann, and George P. Lomonossoff. 2009. "PEAQ: Versatile Expression Vectors for Easy and Quick Transient Expression of Heterologous Proteins in Plants." Plant Biotechnology Journal 7 (7): 682-93. https://doi.org/10.1111/j.14677652.2009.00434.x.

Schmidt, Axel, Betty Wächtler, Ulrike Temp, Trygve Krekling, Armand Séguin, and Jonathan Gershenzon. 2010. "A Bifunctional Geranyl and Geranylgeranyl Diphosphate Synthase Is Involved in Terpene Oleoresin Formation in Picea Abies." Plant Physiology 152 (2): 639-55. https://doi.org/10.1104/pp.109.144691.

Schultz, Bailey J., Seung Yeon Kim, Warren Lau, and Elizabeth S. Sattely. 2019. "Total Biosynthesis for Milligram-Scale Production of Etoposide Intermediates in a Plant Chassis." Journal of the American Chemical Society 141 (49): 19231-35. https://doi.org/10.1021/jacs.9b10717.

Simkin, Andrew J., Karel Miettinen, Patricia Claudel, Vincent Burlat, Grégory Guirimand, Vincent Courdavault, Nicolas Papon, et al. 2013. "Characterization of the Plastidial Geraniol Synthase from Madagascar Periwinkle Which Initiates the Monoterpenoid Branch of the Alkaloid Pathway in Internal Phloem Associated Parenchyma." Phytochemistry 85: 36-43. https://doi.org/10.1016/j.phytochem.2012.09.014.

Song, Chun Peng, Yan Guo, Quansheng Qiu, Georgina Lambert, David W. Galbraith, André Jagendorf, and Jian Kang Zhu. 2004. "A Probable $\mathrm{Na}+(\mathrm{K}+) / \mathrm{H}+$ Exchanger on the Chloroplast Envelope Functions in $\mathrm{PH}$ Homeostasis and Chloroplast Development in Arabidopsis Thaliana." Proceedings of the National Academy of Sciences of the United States of America 101 (27): 10211-16. https://doi.org/10.1073/pnas.0403709101.

Stavrinides, Anna, Evangelos C. Tatsis, Lorenzo Caputi, Emilien Foureau, Clare E.M. Stevenson, David M. Lawson, Vincent Courdavault, and Sarah E. O'Connor. 2016. "Structural Investigation of Heteroyohimbine Alkaloid Synthesis Reveals Active Site Elements That Control Stereoselectivity." Nature Communications 7 (May): 1-14. https://doi.org/10.1038/ncomms12116.

Stephenson, Michael J., James Reed, Nicola J. Patron, George P. Lomonossoff, and Anne Osbourn. 2020. "Engineering Tobacco for Plant Natural Product Production." In Comprehensive Natural Products III: Chemistry and Biology, edited by Hung-Wen (Ben) Liu and Tadhg P. Begley, 3rd ed., 6:244-62. Elsevier Ltd. https://doi.org/10.1016/b978-0-12-409547-2.14724-9.

Ting, Hieng Ming, Bo Wang, Anna Margareta Rydén, Lotte Woittiez, Teun Van Herpen, Francel W.A. Verstappen, Carolien Ruyter-Spira, Jules Beekwilder, Harro J. Bouwmeester, and Alexander Van der Krol. 2013. "The Metabolite Chemotype of Nicotiana Benthamiana Transiently Expressing Artemisinin Biosynthetic Pathway Genes Is a Function of CYP71AV1 Type and Relative Gene Dosage." New Phytologist 199 (2): 352-66. https://doi.org/10.1111/nph.12274. Trenti, Francesco, Kotaro Yamamoto, Benke Hong, Christian Paetz, Yoko Nakamura, and Sarah E. 
O'Connor. 2021. "Early and Late Steps of Quinine Biosynthesis." Organic Letters 23 (5): 179397. https://doi.org/10.1021/acs.orglett.1c00206.

Wang, Bo, Arman Beyraghdar Kashkooli, Adrienne Sallets, Hieng Ming Ting, Norbert C.A. de Ruijter, Linda Olofsson, Peter Brodelius, et al. 2016. "Transient Production of Artemisinin in Nicotiana Benthamiana Is Boosted by a Specific Lipid Transfer Protein from A. Annua." Metabolic Engineering 38: 159-69. https://doi.org/10.1016/j.ymben.2016.07.004.

Wang, Quan, Shihai Xing, Qifang Pan, Fang Yuan, Jingya Zhao, Yuesheng Tian, Yu Chen, Guofeng Wang, and Kexuan Tang. 2012. "Development of Efficient Catharanthus Roseus Regeneration and Transformation System Using Agrobacterium Tumefaciens and Hypocotyls as Explants." BMC Biotechnology 12 (34): 1-12. https://doi.org/10.1186/1472-6750-12-34.

Yamamoto, Kotaro, Dagny Grzech, Konstantinos Koudounas, Emily Amor Stander, Lorenzo Caputi, Tetsuro Mimura, Vincent Courdavault, and Sarah E O'Connor. 2021. "Improved Virus-Induced Gene Silencing Allows Discovery of a Serpentine Synthase Gene in Catharanthus Roseus .” Plant Physiology, 1-12. https://doi.org/10.1093/plphys/kiab285.

Yamamoto, Kotaro, Katsutoshi Takahashi, Lorenzo Caputi, Hajime Mizuno, Carlos E. RodriguezLopez, Tetsushi Iwasaki, Kimitsune Ishizaki, et al. 2019. "The Complexity of Intercellular Localisation of Alkaloids Revealed by Single-Cell Metabolomics." New Phytologist 224 (2): 848-59. https://doi.org/10.1111/nph.16138.

Yamamoto, Kotaro, Katsutoshi Takahashi, Hajime Mizuno, Aya Anegawa, Kimitsune Ishizaki, Hidehiro Fukaki, Miwa Ohnishi, Mami Yamazaki, Tsutomu Masujima, and Tetsuro Mimura. 2016. "Cell-Specific Localization of Alkaloids in Catharanthus Roseus Stem Tissue Measured with Imaging MS and Single-Cell MS." Proceedings of the National Academy of Sciences of the United States of America 113 (14): 3891-96. https://doi.org/10.1073/pnas.1521959113. 
Supplementary Figure S1. Early metabolites of the iridoid pathway are derivatised by endogenous enzymes from $N$. benthamiana.

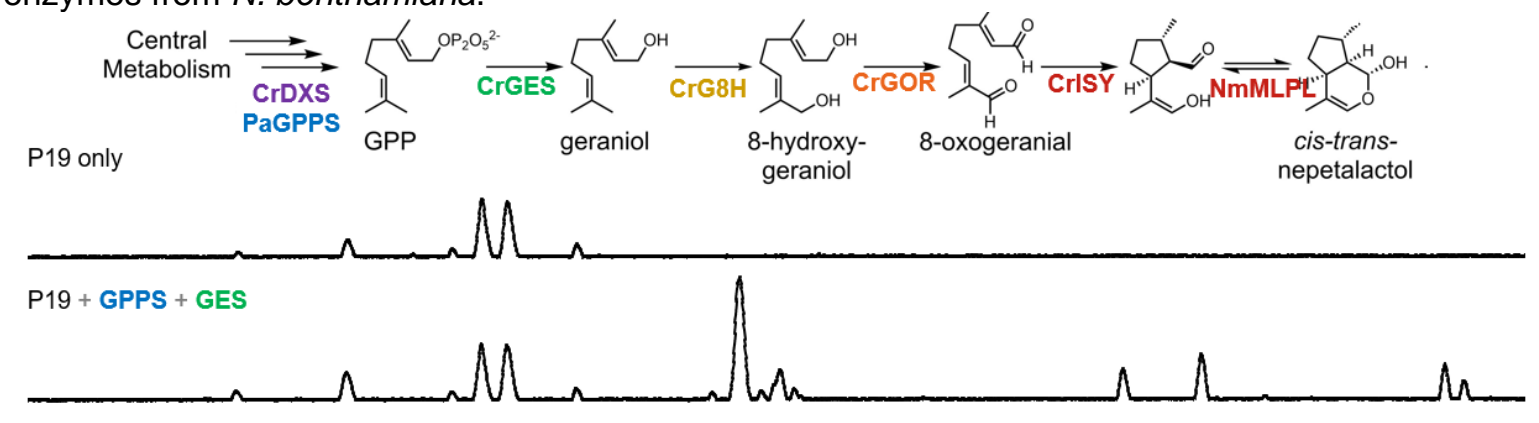

P19 + DXS + GPPS + GES

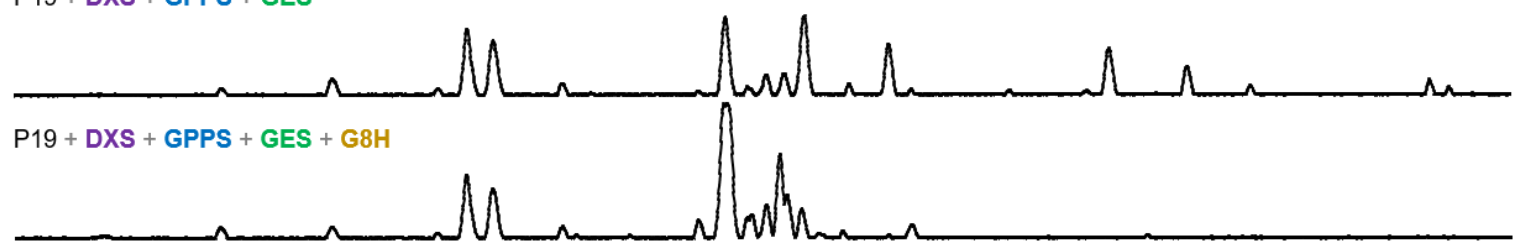

P19 + DXS + GPPS + GES + G8H + GOR

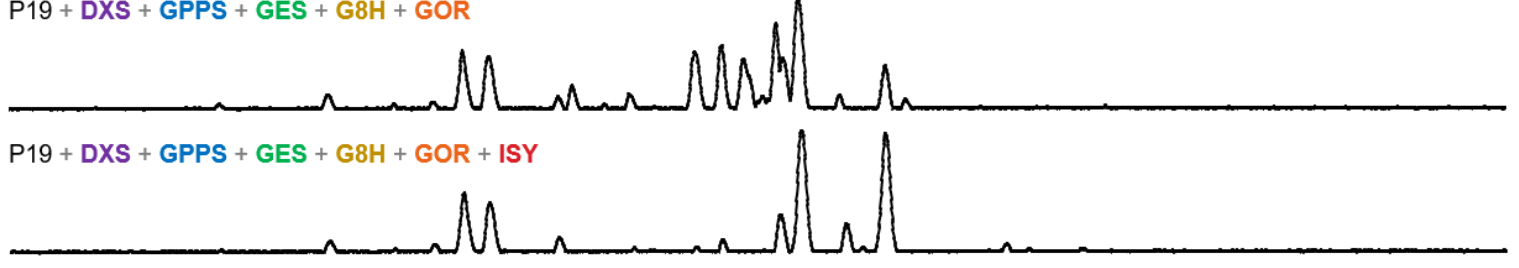

P19 + DXS + GPPS + GES + G8H + GOR + ISY + MLPL

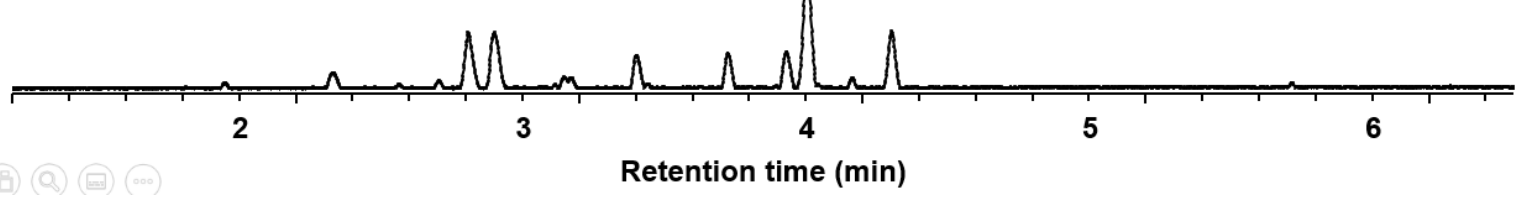


Supplementary Figure S2. Detection of 7-deoxyloganic acid by transient expression in $N$. benthamiana

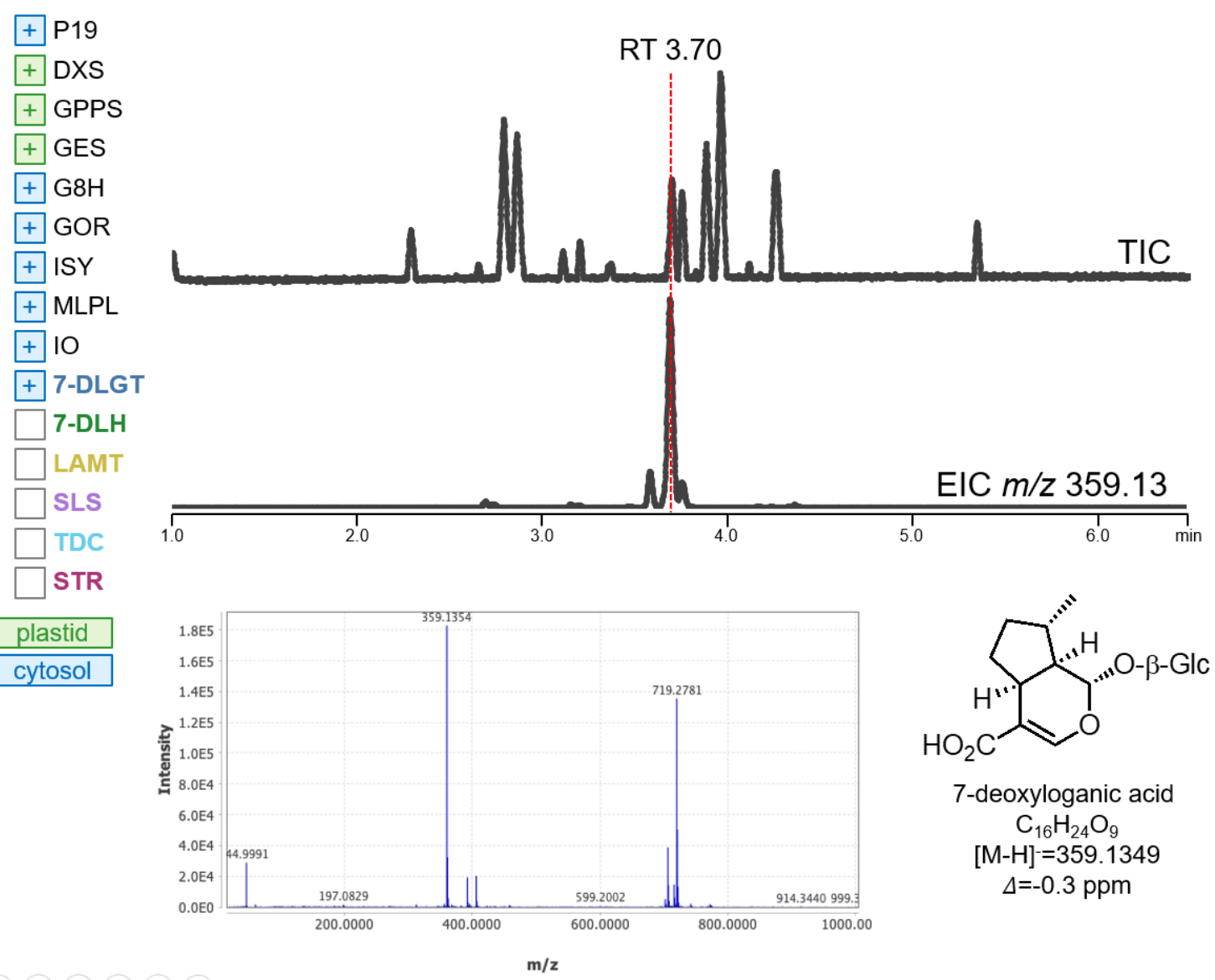


Supplementary Figure S3. Detection of loganic acid by transient expression in $N$. benthamiana

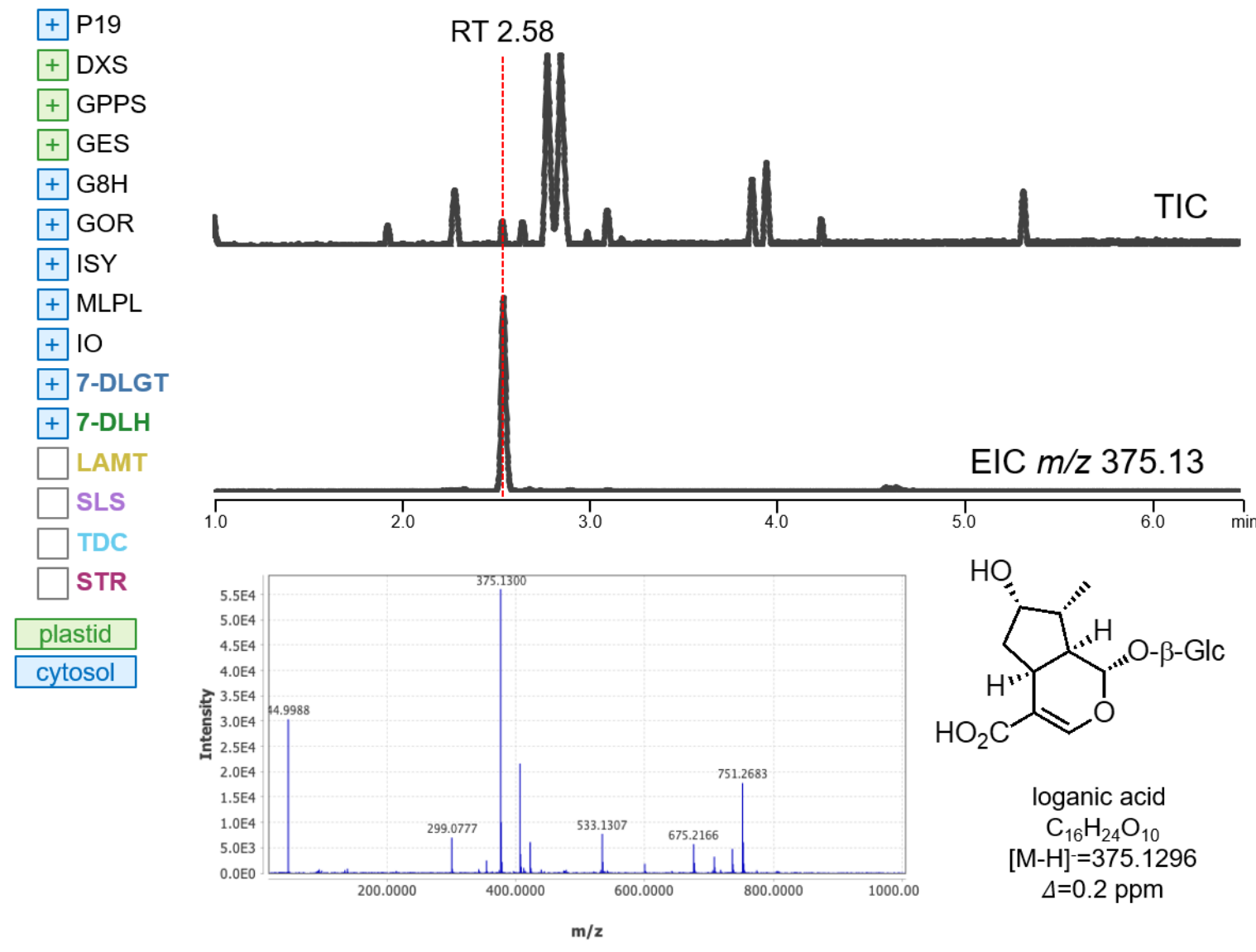


Supplementary Figure S4. Detection of loganin by transient expression in N. benthamiana

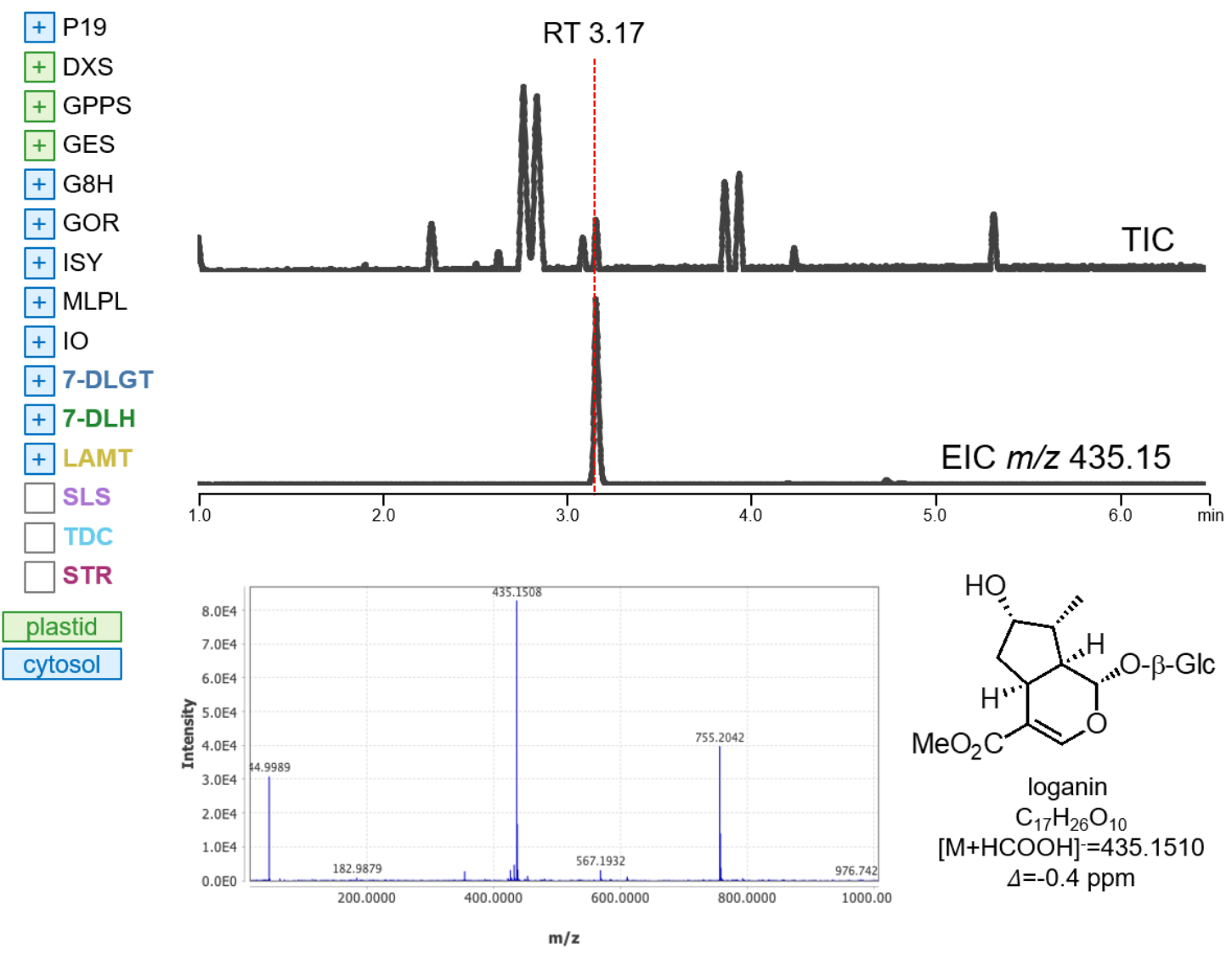


Supplementary Figure S5. Detection of strictosidine by transient expression in $N$. benthamiana

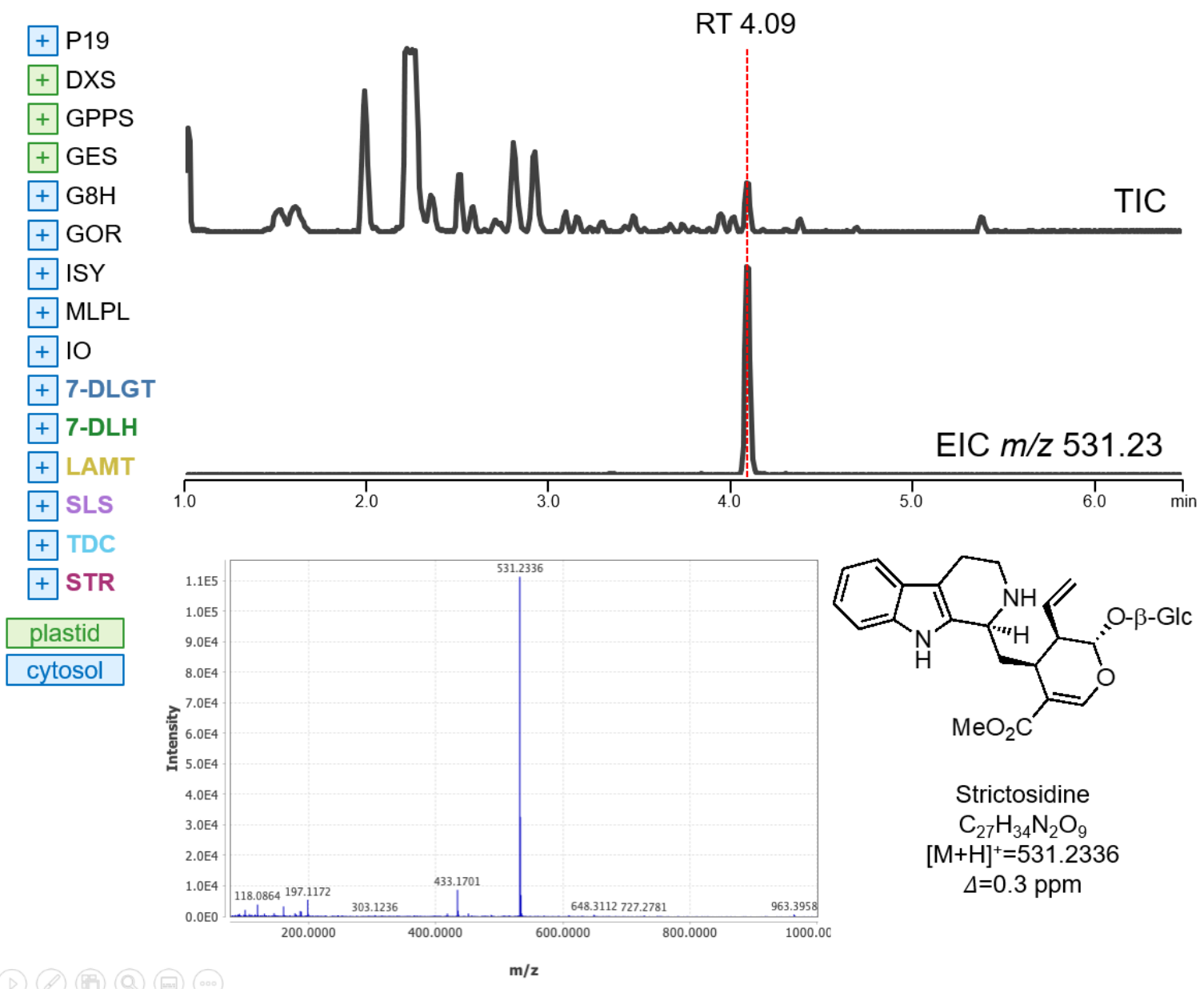


Supplementary Figure S6. Detection of malonyl-strictosidine by transient expression in $N$. benthamiana

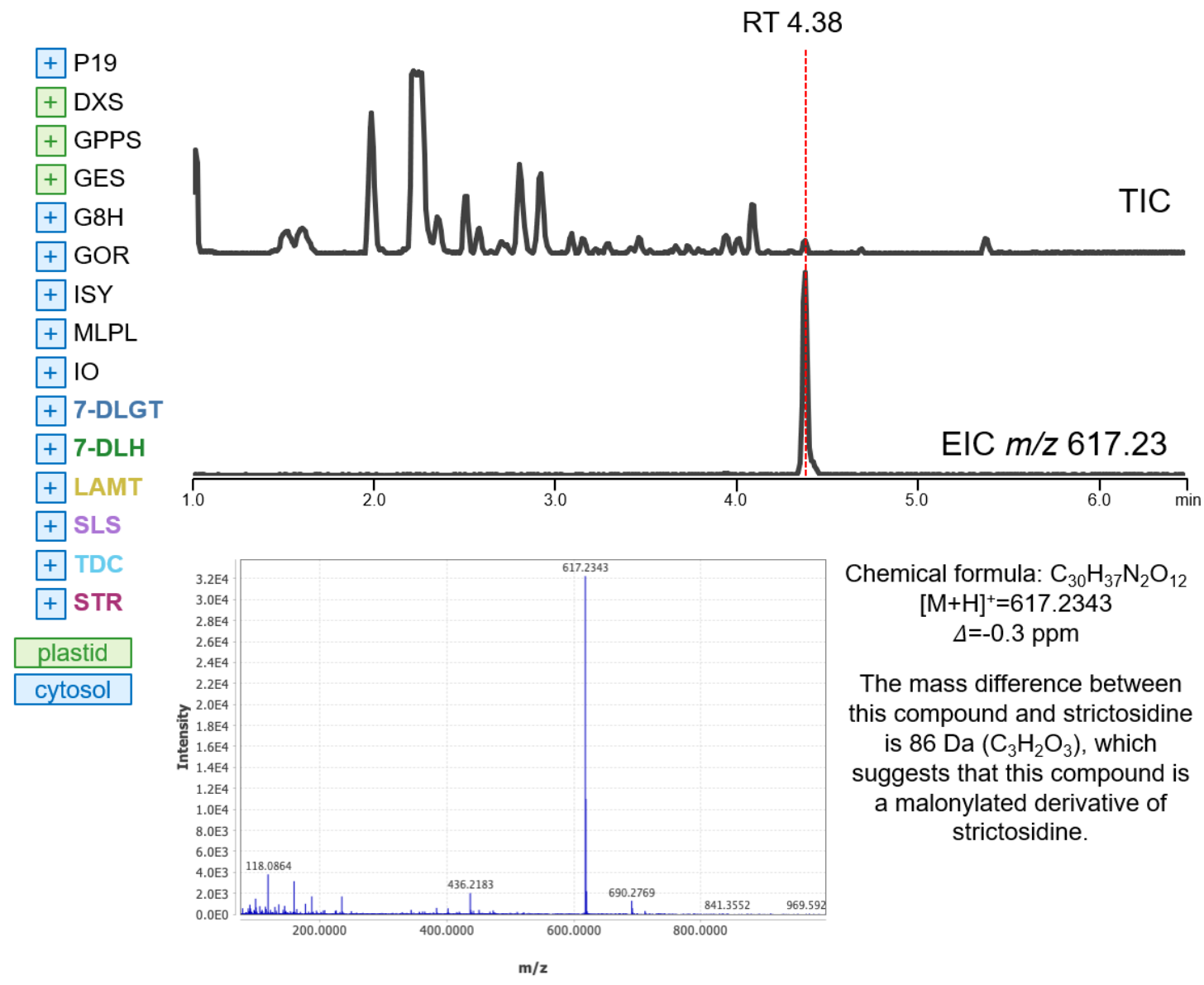


bioRxiv preprint doi: https://doi.org/10.1101/2021.08.12.456143; this version posted August 12, 2021. The copyright holder for this preprint (which was not certified by peer review) is the author/funder, who has granted bioRxiv a license to display the preprint in perpetuity. It is made available under aCC-BY-NC 4.0 International license.

\section{Supplementary Figure S7. Amino acid sequence alignment of candidate GPPS enzymes}

88

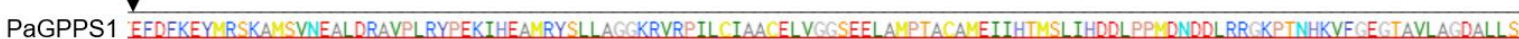
PgGPPS EFDFKEYMRSKAMSVNEALDRAVPLRYPEKIHEAMRYSLLAGGRVRPIL IAACELVGGSEELAMPTACAMEIIHTMSLIHDDLPPM DNDDLRRGKPTNHKVFGEGTAVLAGDALLS

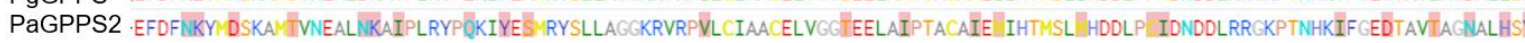

PaGPPS1 FAFEHIAVSTSKTVESDRVLRVVSEL RAICSEGVAGGOVADITSOGNPSVLLETLEWIHIHKTAVLLE SVASGAIIGGA DDEEIERVRKYAR VGLLFOWVDILDVTKSSEELCKT PgGPPS FFAFEHIAVSTSKTVESDRVLRVVSELGRAIGSEGVAGGQVADITSQGNPSVLLETLEWIHIHKTAVLLECSVASGAIIGGA_EGEIERVRKYARCVGLLFQVVDDILDVTKSSEELGKT,

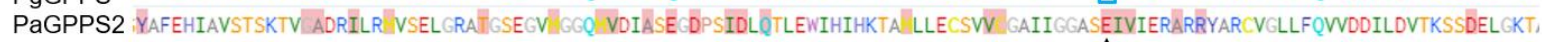

PaGPPS1 AAKDLL SDKATYPKL MGLEKAKEFADELLCKAKEELSFFNPTKAAPLLLLADYIAORON 4.

PgGPPS AAKDLLSDKATYPKLMGLEKAKEFADELLGKAKEELSFFNPTKAAPLLGLADYIAQRON

PaGPPS2 ALKDLISDKATYPKLMGLEKAKEFIIDELLNRAKIELSIIFDPVIKAAPLLGLADYV̈AERON

$$
383
$$

*PaGPPS1: GQ369788.1 - bifunctional GPPS and GGPPS, see Schmidt et al., releases substantial portion of GPP PgGPPS: AHE15048.1, used by Dudley et al. in plasmid 347_pJL1-(CAT7aa)-GPPS_Pgl

PaGPPS2: ACA21458.2, used by Dudley et al. in plasmid 287_pJL1-(CAT5aa)-GPPS2_Pab

* Used in this study as well as Miettinen et al. and Dong et al.

Schmidt et al. Plant Physiology 152:2 693-655 (2010)

Dudley et al. Metab. Eng. 61 251-260 (2020)

Miettinen et al. Nat. Comm. 5:3606 (2014)

Dong et al. New Phytologist 209:2 679-690 (2016) 
bioRxiv preprint doi: https://doi.org/10.1101/2021.08.12.456143; this version posted August 12, 2021. The copyright holder for this preprint (which was not certified by peer review) is the author/funder, who has granted bioRxiv a license to display the preprint in perpetuity. It is made available under aCC-BY-NC 4.0 International license.

Supplementary Table S1. Enzymes and L0 plasmid parts built in this study

\begin{tabular}{|c|c|c|c|c|c|c|c|c|}
\hline Enzyme & Enzyme name & Organism & Abbreviation & Key reference(s) & $\begin{array}{l}\text { GenBank } \\
\text { Accession\# }\end{array}$ & $\begin{array}{c}\begin{array}{c}\text { Level } 0 \text { plasmid name } \\
\text { (AATG-GCTT) }\end{array} \\
\end{array}$ & Addgene\# & Notes \\
\hline DXS & $\begin{array}{l}\text { 1-deoxy-D-xylulose 5- } \\
\text { phosphate synthase }\end{array}$ & $\begin{array}{c}\text { Catharanthus roseus } \\
\text { (Madagascar periwinkle) }\end{array}$ & CrDXS2 & this study & DQ848672 & pEPQDOCM0065 & tbd & $\begin{array}{l}\text { transit peptide removed, amplified from cDNA, } \\
\text { contains R4414K, T533A, A592T mutations } \\
\text { relative to DQ84867272.1 }\end{array}$ \\
\hline tHMGR & $\begin{array}{c}\text { truncated 3-hydroxy-3- } \\
\text { methylglutaryl-coenzyme A } \\
\text { reductase }\end{array}$ & Avena strigosa (oat) & AstHMGR1 & $\begin{array}{l}2017 \text { Reed, Osbourn, Metabolic } \\
\text { Engineering 42: 185-93 }\end{array}$ & KY284573 & pLO-AstHMGR * & tbd & truncated \\
\hline GPPS & $\begin{array}{l}\text { geranyl pyrophosphate } \\
\text { synthase; geranyl } \\
\text { diphosphate synthase }\end{array}$ & $\begin{array}{l}\text { Picea abies } \\
\text { (Norway spruce) }\end{array}$ & PaGPPS1 & $\begin{array}{l}2010 \text { Schmidt, Gershenzon, Plant } \\
\text { Physiology 152(2): 639-55 }\end{array}$ & GQ369788 & pEPQDOCM0818 & tbd & transit peptide removed \\
\hline GES & geraniol synthase & $\begin{array}{l}\text { Catharanthus roseus } \\
\text { (Madagascar periwinkle) }\end{array}$ & CrGES & $\begin{array}{l}2013 \text { Simkin, Memelink, Clastre } \\
\text { Phytochemistiry 85:36-43 }\end{array}$ & JN882024 & pEPQDOCM0063 & tbd & transit peptide removed \\
\hline $\begin{array}{c}\mathrm{G} 8 \mathrm{H} \\
(\mathrm{G} 10 \mathrm{H})\end{array}$ & $\begin{array}{l}\text { geraniol 8-oxidase; geraniol| } \\
\text { 10-hydroxylase; CYP76B6 }\end{array}$ & $\begin{array}{c}\text { Catharanthus roseus } \\
\text { (Madagascar periwinkle) }\end{array}$ & $\mathrm{CrG8H}$ & 2001 Collu FEBS Lett 508(2):215-220 & AJ251269 & pEPQDOCM0058 & tbd & \\
\hline $\begin{array}{c}\text { GOR } \\
(8-\mathrm{HGO}, \\
10 \mathrm{HGO})\end{array}$ & $\begin{array}{c}\text { 8-hydroxygeraniol } \\
\text { oxidoreductase; } 10- \\
\text { hydroxygeraniol } \\
\text { oxidoreductase; alcohol } \\
\text { dehydrogenase } 10 \\
\end{array}$ & $\begin{array}{l}\text { Catharanthus roseus } \\
\text { (Madagascar periwinkle) }\end{array}$ & CrGOR & $\begin{array}{l}2014 \text { Miettinen, Werck-Reichhart } \\
\text { Nat Comm } 5: 3606 ; 2015 \text { r ritikika, } \\
\text { Thulasiram Sci Rep } 58258\end{array}$ & KF302069 & pEPQDOCM0059 & tbd & \\
\hline $\begin{array}{c}\text { ISY } \\
\text { (IRS, IS) }\end{array}$ & iridoid synthase & $\begin{array}{l}\text { Catharanthus roseus } \\
\text { (Madagascar periwinkle) }\end{array}$ & CrISY & \begin{tabular}{|c|}
2012 Geu-Flores, O'Connor Nature \\
492(7427):138-142
\end{tabular} & JX974564 & pEPQDOCM0060 & tbd & \\
\hline MLPL & major latex protein-like & $\begin{array}{c}\text { Nepeta mussinii } \\
\text { (aka Nepeta racemosa) }\end{array}$ & NmMLPL & $\begin{array}{l}2020 \text { Lichman, O'Connor Sci Adv } \\
\text { 6(20) eabao721; } 2019 \text { Lichman, } \\
\text { o'Connor Nat Chem Bio 15 71-79 }\end{array}$ & MT108267.1 & pEPQDOCM0068 & tbd & \\
\hline 10 & iridoid oxidase; CYP76A26 & $\begin{array}{l}\text { Catharanthus roseus } \\
\text { (Madagascar periwinkle) }\end{array}$ & CrlO & $\begin{array}{l}\text { 2014 Miettinen, Werck-Reichhart } \\
\text { Nat Comm 5:3606; 2014 Salim, De } \\
\text { Luca Phytochemistry 101:23-31 }\end{array}$ & KF302066 & pEPQDOCM0061 & tbd & $\begin{array}{l}\text { amplified from CDNA, contains T359S relative to } \\
\text { KF302066 }\end{array}$ \\
\hline 7-DLGT & $\begin{array}{l}\text { 7-deoxyloganetic acid } \\
\text { glucosyl transferase; } \\
\text { UGT709C2 }\end{array}$ & $\begin{array}{l}\text { Catharanthus roseus } \\
\text { (Madagascar periwinkle) }\end{array}$ & Cr7-DLGT & \begin{tabular}{|} 
2014 Miettinen, Werck-Reichhart \\
Nat Comm 5:3606; 2013 Asada Plant \\
Cell 25(10):4123-4134
\end{tabular} & KF302068 & pEPQDOCM0062 & tbd & \\
\hline 7DLH & $\begin{array}{c}\text { 7-deoxyloganic acid } \\
\text { hydroxylase; CYP72A224 }\end{array}$ & $\begin{array}{c}\text { Catharanthus roseus } \\
\text { (Madagascar periwinkle) }\end{array}$ & Cr7DLH & \begin{tabular}{|c|} 
2014 Miettinen, Werck-Reichhart \\
Nat Comm 5 5:3066; 2013 salim, De \\
Luca Plant J 76(5):754:765
\end{tabular} & KF302067 & pEPQDOCM0762 & tbd & \\
\hline LAMT & $\begin{array}{l}\text { loganic acid } \mathrm{O}- \\
\text { methyltransferase }\end{array}$ & $\begin{array}{l}\text { Catharanthus roseus } \\
\text { (Madagascar periwinkle) }\end{array}$ & CrLAMT & $\begin{array}{l}2008 \text { Murata, De Luca Plant Cell } \\
\text { 20(3):524-542 }\end{array}$ & EU057974 & pEPQDOCM0763 & tbd & \\
\hline SLS & $\begin{array}{l}\text { secologanin synthase; } \\
\text { CYP72C }\end{array}$ & $\begin{array}{l}\text { Catharanthus roseus } \\
\text { (Madagascar periwinkle) }\end{array}$ & CrSLS1 & $\begin{array}{l}2000 \text { Irmler, Schroder Plant J } \\
24(6): 797-804\end{array}$ & $\begin{array}{c}\text { KF309242.1 or } \\
\text { KF415117.1 }\end{array}$ & pEPQDOCM0764 & tbd & \begin{tabular}{|c|} 
labeled SLS1 by 2015 Brown, O'Connor, PNAS \\
$112(11)$ 3205-3210 and 2015 Qu, De Luca PNAS \\
$112(192) 6224-6229 ;$ labeled by SLS2 de 2015 \\
Bernonville, Courdavault, BMC Genomics 16(1) \\
619 \\
619
\end{tabular} \\
\hline TDC & tryptophan decarboxylase & $\begin{array}{l}\text { Catharanthus roseus } \\
\text { (Madagascar periwinkle) }\end{array}$ & CrTDC & $\begin{array}{l}1989 \text { De Luca, Brisson PNAS } \\
\text { 86(8):2582-2586 }\end{array}$ & M25151 & pEPQDOCM0765 & tbd & \\
\hline STR & strictosidine synthase & $\begin{array}{c}\text { Catharanthus roseus } \\
\text { (Madagascar periwinkle) }\end{array}$ & CrSTR & $\begin{array}{c}1992 \text { Pasquali, Memelink Plant Mol } \\
\text { Biol 18(6):1121-1131 }\end{array}$ & X61932 & pEPQDOCM0766 & tbd & \\
\hline
\end{tabular}

* pLO-AstHMGR was a generous gift from Anne Osbourn 
bioRxiv preprint doi: https://doi.org/10.1101/2021.08.12.456143; this version posted August 12,2021 . The copyright holder for this preprint (which was not certified by peer review) is the author/funder, who has granted bioRxiv a license to display the preprint in perpetuity. It is made available under aCC-BY-NC 4.0 International license.

Supplementary Table S2. Level 1 plasmids for A. tumefaciens - mediated transient expression in $N$. benthamiana

\begin{tabular}{|c|c|c|c|c|}
\hline & $\begin{array}{l}\text { Promoter }+5^{\prime} \text { UTR + } \\
\text { cTP(opt) }\end{array}$ & CDS & $\begin{array}{c}\text { 3'UTR + } \\
\text { Terminator }\end{array}$ & $\begin{array}{l}\text { Level } 1 \\
\text { Acceptor }\end{array}$ \\
\hline & GGAG-TACTTACT-AATG & AATG-GCTT & GCTT-CGCT & CGCT-GGAG \\
\hline pEPQD1CB0104 (P6_3 & plCH51277 & plCH44022 & pUAP41414 & plCH47781 \\
\hline pEPQD1CB0817 (P1_35SshortTMV-AstHMGR-35Sterm) & plCH51277 & pLO-AstHMGR & pUAP41414 & \\
\hline pEPQD1CB0107 (P1_35SshortTMV-cTP_CrDXS2-35Sterm) & \begin{tabular}{|l|l|} 
plCH41388 & plCH78133 \\
\end{tabular} & pEPQD0CM0065 & pUAP41414 & plCH47732 \\
\hline pEPQD1CB0108 (P2_35SshortTMV-PaGPPS1-35Sterm) & plCH51277 & pEPQD0CM0818 & pUAP41414 & plCH47742 \\
\hline pEPQD1CB0109 (P2_35SshortTMV-cTP_PaGPPS1-35Sterm) & \begin{tabular}{|l|l|} 
plCH41388 & plCH78133 \\
\end{tabular} & pEPQD0CM0818 & pUAP41414 & plCH47742 \\
\hline pEPQD1CB0110 (P3_35SshortTMV-CrGES-35Sterm) & plCH51277 & pEPQD0CM0063 & pUAP41414 & $\mathrm{plCH} 47751$ \\
\hline pEPQD1CB0112 (P3_35SshortTMV-cTP_CrGES-35Sterm) & $\mathrm{ICH} 41388$ plCH78 & pEPQD0 & $\mathrm{pUA}$ & \\
\hline pEPQD1CB0113 (P4_35SshortTMV-CrG8H-35Sterm) & plCH51277 & pEPQD0CM0058 & pUAP41414 & plCH47761 \\
\hline pEPQD1CB0114 (P4 35SshortTMV-cTP CrG8H-35St & $41388 \mathrm{plCH} 7$ & PEPQD0 & 1414 & 7761 \\
\hline pEPQD1CB0115 (P5 35SshortTMV-Cr8HGO/GOR-35Sterm) & plCH51277 & pEPQDO & $\mathrm{PUAF}$ & plCH47772 \\
\hline pEPQD1CB0116 (P5_35SshortTMV-cTP_Cr8HGO/GOR-3 & $\mathrm{plCH} 41388 \mathrm{plCH} 7$ & pEPQD0CM0059 & $\mathrm{pU}$ & 7772 \\
\hline pEPQD1C & plCH51277 & pEPQD0CM0060 & $\mathrm{pUA}$ & $\mathrm{plCl}$ \\
\hline pEPQD1CB0118 (P6_35Sshort & plCH41388 plCH78133 & pEPQD0CM0060 & $\mathrm{pUA}$ & plCH47781 \\
\hline pEPQD1CB0119 (P1_35Sshor & plCH51277 & $\mathrm{pEPQDO}$ & $\mathrm{pUA}$ & 7732 \\
\hline pEPQD1CB0120 (P1_35Ssho & plCH41388 plCH78 & pEPQD0 & $\mathrm{pUA}$ & $\mathrm{plCl}$ \\
\hline pEPQD1CB0121 (P2_35Sshort & plCH51277 & pEPQD0 & 1414 & plCH47742 \\
\hline pEPQD1CB01 & plCH41388 plCH78 & pEPQDO & $\mathrm{pUA}$ & $\mathrm{plCl}$ \\
\hline 3 (P3_35Sshor & plCH51277 & pEPQD0CM0062 & pUA & plCH47751 \\
\hline pEPQD1CB0124 (P3_35SshortTMV-cTP_CrDLGT-35Sterm) & $\mathrm{plCH} 41388 \mathrm{plCH} 7$ & pEPQD0CM0062 & pUAP41414 & plCH47751 \\
\hline pEPQD1CB0767 (P4_35SshortTMV-Cr7DLH-35Sterm) & plCH51277 & pEPQD & pUA & plCH47761 \\
\hline pEPQD1CB0768 (P4_35SshortTMV-cTP_Cr7DLH-35Sterm) & \begin{tabular}{|l|l|} 
plCH41388 & plCH78133 \\
\end{tabular} & $\mathrm{pEPQE}$ & PUAF & plCH47761 \\
\hline pEPQD1CB0769 (P5_35SshortTMV- CrLAMT-35Sterm) & plCH51277 & $\mathrm{pEPQE}$ & $\mathrm{pUA}$ & plCH47772 \\
\hline pEPQD1CB0770 (P5_35SshortTMV-cTP_CrL & \begin{tabular}{|l|l|} 
plCH41388 & plCH78133 \\
\end{tabular} & pEPQD0CM0763 & pUA & plCH47772 \\
\hline pEPQD1CB0771 (P6 35SshortTMV- CrSLS-35Sterm) & plCH51277 & pEPQD0CM0764 & pUAP41414 & plCH47781 \\
\hline pEPQD1CB0772 (P6 35SshortTMV-cTP CrSLS-35Sterm) & \begin{tabular}{l|l|} 
plCH41388 & plCH78133 \\
\end{tabular} & pEPQDO & pUAP41414 & plCH47781 \\
\hline pEPQD1CB0773 (P1 35SshortTMV-CrTDC-35Sterm) & plCH51277 & pEPQDOCMO & pUAP41414 & plCH47732 \\
\hline pEPQD1CB0774 (P1_35SshortTMV-cTP_CrTDC-3 & \begin{tabular}{l|l}
$\mathrm{CH} 41388$ & $\mathrm{plCH} 7$ \\
\end{tabular} & pEPQI & pUA & plCH47732 \\
\hline pEPQD1CB0775 (P2 35SshortTMV- CrSTR-35Sterm) & plCH51277 & pEPQDOCN & pUAP41414 & plCH47742 \\
\hline pEPQD1CB0776 (P2 35SshortTMV-cTP CrSTR-35Sterm) & \begin{tabular}{l|l} 
plCH41388 & plCH78133 \\
\end{tabular} & pEPQD 0CM076 & pUAP41414 & plCH47742 \\
\hline
\end{tabular}

Level 0 parts from MoClo kit

pICH51277 (CMV 35S short promoter + TMV omega 5'UTR) Addgene\#50268

plCH41388 (CMV 35S short promoter) Addgene\#50253

plCH78133 ( TMV omega 5'UTR + synthetic chloroplast transit peptide RbcS) Addgene\#50292

pUAP41414 (CMV 3'UTR + terminator) Addgene\#50337

plCH44022 (LO, P19 CDS) Addgene\#50330

plCH47732 (L1 P1 acceptor forward) Addgene\#48000

plCH47742 (L1 P2 acceptor forward) Addgene\#48001

plCH47751 (L1 P3 acceptor forward) Addgene\#48002

plCH47761 (L1 P4 acceptor forward) Addgene\#48003

plCH47772 (L1 P5 acceptor forward) Addgene\#48004

plCH47781 (L1 P6 acceptor forward) Addgene\#48005

Abbreviations

$\mathrm{CMV}=$ Cauliflower mosaic virus

TMV = Tobacco Mosaic Virus

P19 suppressor of gene silencing (Tomato Bushy Stunt Virus)

cTP $=$ chloroplast transit peptide 